\title{
Fungal transformation of selenium and tellurium located in a volcanogenic sulfide deposit
}

\author{
Xinjin Liang, ${ }^{1 \dagger}$ Magali Aude Marie-Jeanne Perez, ${ }^{2}$ \\ Shuai Zhang, ${ }^{3 *}$ Wenjuan Song, ${ }^{1,4}$ \\ Joseph Graham Armstrong, ${ }^{5}$ Liam Adam Bullock, ${ }^{5}$ \\ Jörg Feldmann, ${ }^{2}$ John Parnell, ${ }^{5}$ Laszlo Csetenyi ${ }^{6}$ and \\ Geoffrey Michael Gadd (1) 1,7* \\ ${ }^{1}$ Geomicrobiology Group, School of Life Sciences, \\ University of Dundee, Dundee DD1 5EH, Scotland, UK. \\ ${ }^{2}$ Trace Element Speciation Laboratory (TESLA), \\ Department of Chemistry, King's College, Meston Walk, \\ University of Aberdeen, Aberdeen AB24 3UE, \\ Scotland, UK. \\ ${ }^{3}$ School of Science and Engineering, University of \\ Dundee, Dundee DD1 4HN, Scotland, UK. \\ ${ }^{4}$ Xinjiang Institute of Ecology and Geography, Chinese \\ Academy of Sciences, Urumqi, 830011, China. \\ ${ }^{5}$ Department of Geology and Petroleum Geology, King's \\ College, Meston Walk, University of Aberdeen, AB24 \\ 3UE, Aberdeen, Scotland, UK. \\ ${ }^{6}$ Concrete Technology Group, Department of Civil \\ Engineering, University of Dundee, Dundee, \\ Scotland, UK. \\ ${ }^{7}$ State Key Laboratory of Heavy Oil Processing, Beijing \\ Key Laboratory of Oil and Gas Pollution Control, College \\ of Chemical Engineering and Environment, China \\ University of Petroleum, 18 Fuxue Road, Changping \\ District, 18 Fuxue Road, Changping District, Beijing, \\ 102249, China.
}

\section{Summary}

Microbial reduction of soluble selenium (Se) or tellurium (Te) species results in immobilization as elemental forms and this process has been employed in soil bioremediation. However, little is known of direct and indirect fungal interactions with Se-/Te-bearing ores. In this research, the ability of Phoma glomerata to

Received 20 February, 2020; accepted 1 April, 2020. *For correspondence. E-mail g.m.gadd@dundee.ac.uk; Tel. (+44) 1382 384767. 'Present addresses: Sustainable Environment Research Centre, Upper Glyntaff, University of South Wales, Pontypridd, Wales, CF37 4BD, UK; "School of Mechanical and Aerospace Engineering, Queen's University, Belfast, BT9 5AG, UK; ${ }^{\S}$ Ocean and Earth Science, University of Southampton, National Oceanography Centre, Southampton, SO14 3ZH, UK. effect transformation of selenite and tellurite was investigated including interaction with Se and Te present in sulfide ores from the Kisgruva Proterozoic volcanogenic deposit. Phoma glomerata could precipitate elemental Se and Te as nanoparticles, intracellularly and extracellularly, when grown with selenite or tellurite. The nanoparticles possessed various surface capping molecules, with formation being influenced by extracellular polymeric substances. The presence of sulfide ore also affected the production of exopolysaccharide and protein. Although differences were undetectable in gross $\mathrm{Se}$ and $\mathrm{Te}$ ore levels before and after fungal interaction using $X$-ray fluorescence, laser ablation inductively coupled plasma mass spectrometry of polished flat ore surfaces revealed that $P$. glomerata could effect changes in Se/Te distribution and concentration indicating $\mathrm{Se} / \mathrm{Te}$ enrichment in the biomass. These findings provide further understanding of fungal roles in metalloid transformations and are relevant to the geomicrobiology of environmental metalloid cycling as well as informing applied approaches for $\mathrm{Se}$ and $\mathrm{Te}$ immobilization, biorecovery or bioremediation.

\section{Introduction}

Selenium (Se) and tellurium ( $\mathrm{Te}$ ) species can be transformed through oxidation, reduction, methylation and demethylation by microorganisms (Gadd, 1993; Jacob et al., 2016; Eswayah et al., 2016). Such processes are important components of natural biogeochemical cycles for these elements in natural aquatic and terrestrial environments as well as those polluted with potentially toxic levels (Gadd, 1993, 2007, 2010; Rosenfeld et al., 2017). Reduction and methylation in particular have been employed successfully for bioremediation of Se-contaminated waters and sediments through immobilization and volatilization respectively (e.g. Lawson and Macy, 1995; Cantafio et al., 1996; Brady et al., 1996; Soda et al., 2012; Mal et al., 2017; Piacenza et al., 2018a,b). In recent years, with growing concern

(C) 2020 The Authors. Environmental Microbiology published by Society for Applied Microbiology and John Wiley \& Sons Ltd. This is an open access article under the terms of the Creative Commons Attribution License, which permits use, distribution and reproduction in any medium, provided the original work is properly cited. 
about the security of supply of strategic elements for electronic, digital and environmentally sustainable (bio) technologies, microbial processes are viewed as an important part of the suite of approaches that may be necessary for element biorecovery (Nancharaiah et al., 2016; Liang and Gadd, 2017). The application of microbial Se or Te oxyanion reduction offers a potential route for biorecovery of these elements since extensive extracellular precipitation of elemental Se or Te can occur in solution (Gharieb et al., 1999; Baesman et al., 2007; Espinosa-Ortiz et al., 2017; Liang et al., 2019). However, little is known about direct fungal interactions with Se- or Te-containing mineral deposits, and their applied or environmental significance, particularly in the solid phase.

The ores at the massive Kisgruva Proterozoic volcanogenic sulfide deposit in the Kongsberg region of Buskerud, Norway, were originally used for extraction of copper, iron and sulfur. However, they also contain high concentrations of Se and Te (Bjerkgård, 2015; Bullock et al., 2018; Kotková et al., 2018). The Se and Te in these ores are primarily retained in pyrite and chalcopyrite as selenides and tellurides with selenite and tellurite occurring at ore surfaces as oxidized weathering products (Bullock et al., 2018). Little is known about fungal interactions with $\mathrm{Se}$ and Te species present in ores and their ability to effect changes in chemical state or mobility, although it is known that fungi can have significant effects on ores and substrates containing other metals. For example, the wood-rotting basidiomycete Schizophyllum commune can bioweather black slate through hyphal mechanical pressure and biochemical mechanisms such as siderophore, laccase and organic acid excretion (Kirtzel et al., 2020). Aspergillus niger can mediate direct and indirect bioleaching of cobalt from low grade laterite and pyritic ores (Yang et al., 2019, 2020). Fungal bioweathering, involving both mineral dissolution and biomineralization mechanisms, has also been demonstrated for silicate and sulfide ores (Wei et al., 2012a, 2013), manganese oxides including birnessite (Wei et al., 2012b), mimetite (Ceci et al., 2015a), and vanadinite (Ceci et al., 2015b). Investigation of fungal interactions with Kisgruva sulfide ore can provide understanding of how heterogeneously distributed critical elements, like Se and Te, may be transformed or accumulated by fungi. This may be significant for environmental metalloid cycling as well as novel approaches for Se and Te immobilization, bioremediation or biorecovery. Therefore, this research has examined the capability of Phoma glomerata as a selenite- and/or tellurite-reducing microorganism and further examined its potential to interact with and accumulate $\mathrm{Se}$ and $\mathrm{Te}$ from samples from the Kisgruva volcanogenic sulfide deposit. Specific objectives were to characterize extracellular and intracellular deposition of Se and Te nanoparticles, including the role of extracellular polymeric substances, effects of $\mathrm{Se} / \mathrm{Te}$ oxyanions on growth and morphology, and fungal accumulation of $\mathrm{Se}$ and $\mathrm{Te}$ from resources present in the sulfide ores.

\section{Results and discussion}

Effects of selenite and tellurite on growth and morphology of P. glomerata

In order to examine the effects of Se and Te oxyanions on growth and morphology, $1 \mathrm{mM}$ sodium selenite or sodium tellurite was incorporated in AP1 liquid media and growth of $P$. glomerata recorded after 30 days. Control $P$. glomerata hyphae showed a typical appearance and smooth surface texture (Fig. 1Aa), whereas hyphae grown with selenite (Fig. 1Ba) or tellurite (Fig. 1Ca) appeared thinner with a shrunken appearance and a loose surface texture (Fig. 1). The subcellular architecture of $P$. glomerata was investigated using a confocal microscope after addition of Hoechst 33342 which reveals nuclear distribution. Control mycelium possessed elongated nuclei (Fig. 1Ac), while the addition of selenite and tellurite increased septation in the hyphae (Fig. 1Bc and (C), and swelling was observed from the hyphal tip with addition of tellurite (Fig. 1Cc). The nuclear density on addition of selenite and tellurite was increased compared to controls. These observations complement other research on the effect of different Se levels on growth of Pleurotus eryngii (Kim et al., 2014). A biomass reduction and increased septation also occurred when $P$. eryngii was grown at $1 \mathrm{mM}$ Se (Kim et al., 2014). It has also been found that selenite was capable of binding to polysaccharides and was particularly linked to chitin in the cell wall of Pleurotus ostreatus (Munoz et al., 2006). Low concentrations of selenite can stimulate fungal growth reflecting its importance as an essential element (Munoz et al., 2006; Kim et al., 2014).

\section{Formation of elemental Se and Te during growth of P. glomerata}

Nanoparticles formed on fungal surfaces and in the medium during growth of $P$. glomerata with selenite/ tellurite. Spherical Se-containing particles occurred in fungal supernatants after growth with selenite (Fig. 2A), while needle-shaped particles (nanorods) formed after growth with tellurite (Fig. 2B). The Te nanorods harvested from $P$. glomerata culture supernatants clustered together being composed of numerous individual shards (Fig. 2B). Particle size analysis revealed that the particles formed after fungal growth with $\mathrm{Na}_{2} \mathrm{SeO}_{3}$ or $\mathrm{Na}_{2} \mathrm{TeO}_{3}$ showed significant variability. The average diameter of 
Se-containing particles ranged from 100 to $200 \mathrm{~nm}$, with a high proportion of sizes less than $140 \mathrm{~nm}$ (Fig. 2C). The particle size (width) of tellurite-containing particles ranged from 10 to $80 \mathrm{~nm}$, with a high proportion of sizes less than $40 \mathrm{~nm}$ (Fig. 2D). The particle size measurements provide an average diameter for spherical shapes,

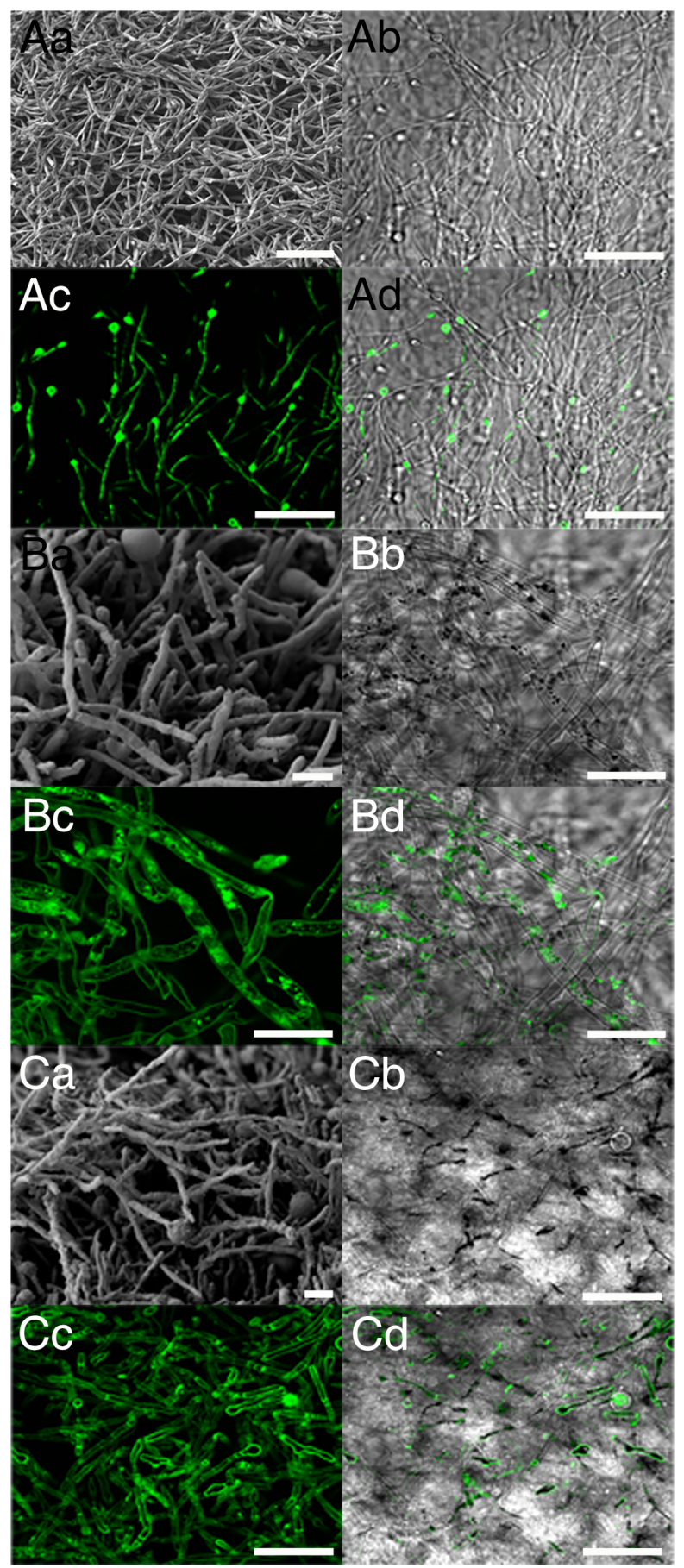

but are not so applicable for the Te nanorods where width measurements were used.

Energy-dispersive X-ray analysis (EDXA) was used to elucidate the elemental composition of the particles produced by $P$. glomerata. Most particles generated after growth with $1 \mathrm{mM} \mathrm{Na}_{2} \mathrm{SeO}_{3}$ showed peaks for carbon, oxygen and Se as the main elements (Fig. 2E). Similarly, particles generated after fungal growth in AP1 medium amended with $1 \mathrm{mM} \mathrm{Na}_{2} \mathrm{TeO}_{3}$ showed peaks for carbon, oxygen and Te as the main elements (Fig. 2F). XRD data showed that the Se-containing particles produced by $P$. glomerata showed a match to reference patterns for elemental Se (Se), while the Te-containing particles produced by $P$. glomerata matched elemental Te (Te) (Fig. 3). The formation of spherical-shaped elemental Se and needle-shaped elemental Te particles conforms to previously published findings (Mandal et al., 2006; Baesman et al., 2007; Bajaj et al., 2012; Aborode et al., 2015; Borghese et al., 2016; Rosenfeld et al., 2017; Espinosa-Ortiz et al., 2015a,b, 2016a,b,c, 2017). Reduction of selenite and tellurite to elemental Se and Te can occur intracellularly (Gharieb and Gadd, 1998, 2004; Gharieb et al., 1999; Debieux et al., 2011; Sonkusre et al., 2014; Li et al., 2014; Espinosa-Ortiz et al., 2017) and/or extracellularly (Oremland et al., 2004; Baesman et al., 2007; Zhang et al., 2012; Jiang et al., 2012; Bajaj et al., 2012; Vetchinkina et al., 2013; Borghese et al., 2016) among different microorganisms. In this study, it appeared that elemental Se and Te formed both intracellularly, as shown in the DIC images (Fig. 1Bb and $\mathrm{Cb}$ ), and extracellularly. Extracellular production of elemental Se and Te resulted in particles that could reach sizes of

Fig. 1. SEM, differential interference contrast (DIC) imaging and confocal microscopy (CM) of $P$. glomerata grown in AP1 liquid media amended with $1 \mathrm{mM} \mathrm{Na} \mathrm{SeO}_{3}$ or $\mathrm{Na}_{2} \mathrm{TeO}_{3}$.

A. P. glomerata grown in AP1 medium as the control, (Aa) SEM of $P$. glomerata mycelium, (Ab) DIC image of $P$. glomerata mycelium, (Ac) CM of $P$. glomerata nuclear distribution after Hoechst 33342 staining, (Ad) superimposed images of DIC and Hoechst 33342 staining. Scale bars: Aa $10 \mu \mathrm{m}, \mathrm{Ab}-\mathrm{d} 50 \mu \mathrm{m}$.

B. $P$. glomerata grown in AP1 medium amended with $1 \mathrm{mM}$ $\mathrm{Na}_{2} \mathrm{SeO}_{3}$, (Ba) SEM of $P$. glomerata mycelium grown with $\mathrm{Na}_{2} \mathrm{SeO}_{3}$, (Bb) DIC image of $P$. glomerata mycelium grown with $\mathrm{Na}_{2} \mathrm{SeO}_{3}$, (Bc) $\mathrm{CM}$ of nuclear distribution of $P$. glomerata grown with $\mathrm{Na}_{2} \mathrm{SeO}_{3}$ after Hoechst 33342 staining, (Bd) superimposed images of DIC and Hoechst 33342 staining of $P$. glomerata grown with $\mathrm{Na}_{2} \mathrm{SeO}_{3}$. Scale bars: Ba $10 \mu \mathrm{m}, \mathrm{Bb}-\mathrm{d} 20 \mu \mathrm{m}$.

C. P. glomerata grown in AP1 medium amended with $1 \mathrm{mM}$ $\mathrm{Na}_{2} \mathrm{TeO}_{3}$, (Ca) SEM of $P$. glomerata mycelium grown with $\mathrm{Na}_{2} \mathrm{TeO}_{3}$, (Cb) DIC image of $P$. glomerata mycelium grown with $\mathrm{Na}_{2} \mathrm{TeO}_{3}$, (C) $\mathrm{CM}$ of nuclear distribution of $P$. glomerata grown with $\mathrm{Na}_{2} \mathrm{TeO}_{3}$ after Hoechst 33342 staining, (Cd) superimposed images of DIC and Hoechst 33342 staining of $P$. glomerata grown with $\mathrm{Na}_{2} \mathrm{TeO}_{3}$. Scale bars: Ca $10 \mu \mathrm{m}, \mathrm{Cb}-\mathrm{d} 50 \mu \mathrm{m}$. Phoma glomerata, with or without selenite and tellurite, was grown for 30 days at $25^{\circ} \mathrm{C}$ in the dark on an orbital shaking incubator at $125 \mathrm{rpm}$. Typical images are shown from one of at least three examinations. 


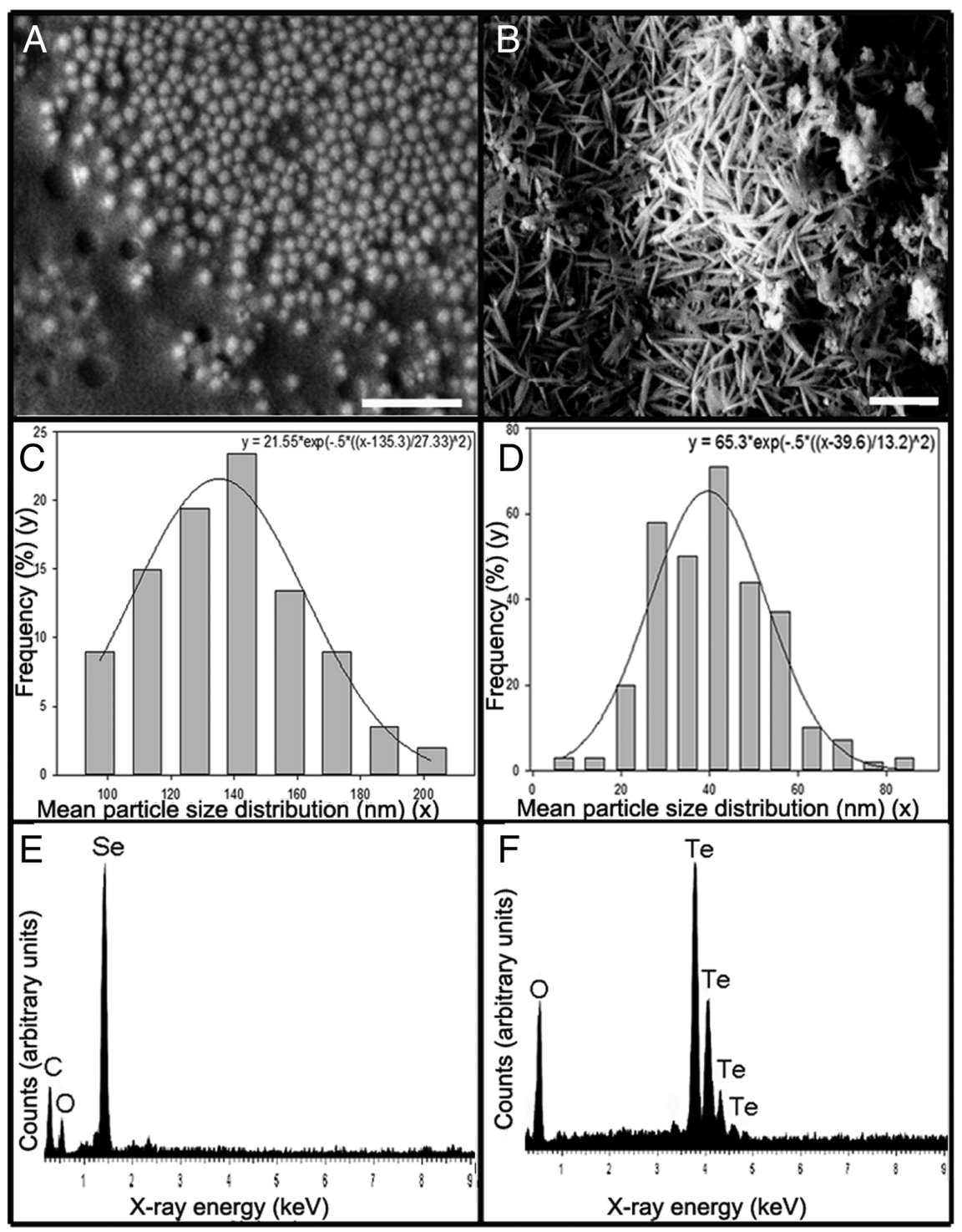

Fig. 2. SEM, PSD and energy dispersive $X-$ ray analysis of nanoparticles harvested from spent culture medium supernatants after growth of $P$. glomerata with $1 \mathrm{mM} \mathrm{Na}_{2} \mathrm{SeO}_{3}$ or $\mathrm{Na}_{2} \mathrm{TeO}_{3}$. Nanoparticles harvested from the supernatant of $P$. glomerata grown in (A) $\mathrm{Na}_{2} \mathrm{SeO}_{3}$ - or (B) $\mathrm{Na}_{2} \mathrm{TeO}_{3}$-amended AP1 medium. Scale bars: $A=1 \mu \mathrm{m}$, $B=500 \mathrm{~nm}$. Size distribution of particles generated from $P$. glomerata growth with (C) $\mathrm{Na}_{2} \mathrm{SeO}_{3}$ or (D) $\mathrm{Na}_{2} \mathrm{TeO}_{3}$. (E) Se- or (F) tellurium-containing particles produced by $P$. glomerata (shown in A, B). Phoma glomerata was grown in AP1 liquid media amended with $1 \mathrm{mM} \mathrm{Na} \mathrm{SeO}_{3}$ or $\mathrm{Na}_{2} \mathrm{TeO}_{3}$ for 30 days at $25^{\circ} \mathrm{C}$ in the dark on an orbital shaking incubator at $125 \mathrm{rpm}$. Typical images, measurements and spectra are shown from one of at least three examinations.

around $140 \mathrm{~nm}\left(\mathrm{Se}^{0}\right)$ (Fig. $\left.2 \mathrm{C}\right)$ and $80 \mathrm{~nm}\left(\mathrm{Te}^{0}\right)$ as mentioned previously (Fig. 2D). From our observations, it seemed the majority of biogenic Se and Te nanoparticles were generated extracellularly.

The influence of selenite or tellurite on fluorescent components of EPS

Excitation emission matrix (EEM) fluorescence spectra of the extracellular polymeric substance (EPS) produced by $P$. glomerata grown without (Fig. 4A) or with $1 \mathrm{mM}$ $\mathrm{Na}_{2} \mathrm{SeO}_{3}$ (Fig. 4B) or $1 \mathrm{mM} \mathrm{Na} \mathrm{NeO}_{3}$ (Fig. 4C) are shown in Fig. 4. Three excitation peaks were identified for the EPS extracted from $P$. glomerata grown without selenite or tellurite: peak A 2700 (Ex/Em $370 / 460 \mathrm{~nm}$ ), peak B 395.2 (Ex/Em 290/360 nm) and peak C
848 (Ex/Em 270/465 nm). These peaks correspond to humic acid-like substances (peak A), tryptophan and protein-like soluble microbial by-products (peak B), and fulvic acid-like and humic acid-like substances (peak $C$ ) (Chen et al., 2003). Only one excitation peak was found for the EPS extracted from $P$. glomerata grown with selenite or tellurite: peak 2308 (Ex/Em 370/455 nm) for selenite and peak 1455 (Ex/Em 375/456 nm) for tellurite, both being classed as indicating humic acid-like substances (Chen et al., 2003). Previous research has demonstrated that exopolysaccharide from Lactococcus lactis was able to react with $\mathrm{Se}$ chloride oxide and generate Seexopolysaccharide (Se-EPS) (Guo et al., 2013). Gold nanoparticles (AuNPs) were formed and aggregated at $\mathrm{pH} 2$ in a cell-free extract of Avena sativa (Armendariz et al., 2004). The formation of these aggregates was due 


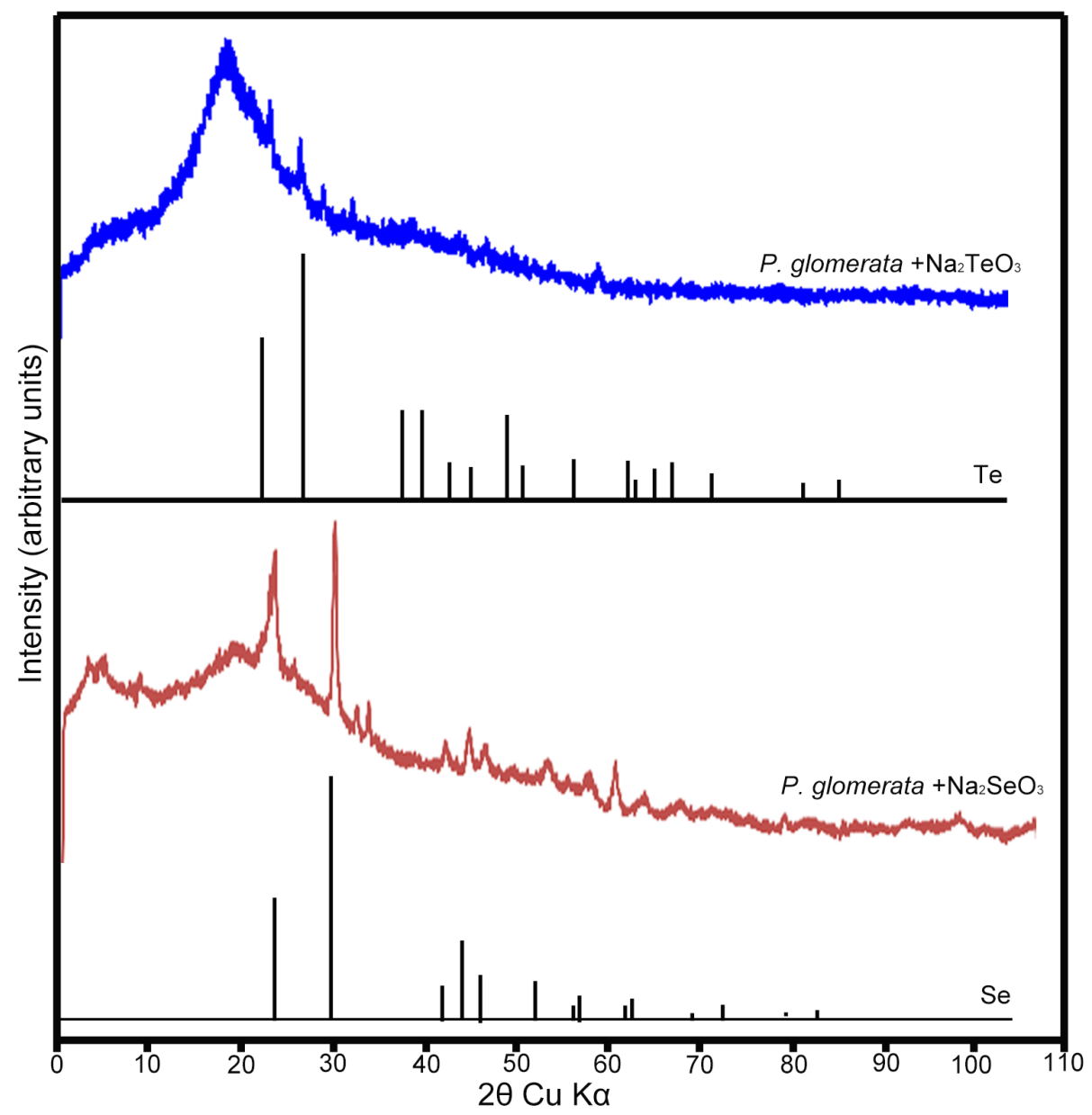

Fig. 3. X-ray powder diffraction patterns of particles formed in $1 \mathrm{mM}$ $\mathrm{Na}_{2} \mathrm{SeO}_{3}$ - or $\mathrm{Na}_{2} \mathrm{TeO}_{3}$-amended $\mathrm{AP} 1$ liquid medium after growth of P. glomerata at $25^{\circ} \mathrm{C}$ in the dark at $125 \mathrm{rpm}$ for 30 days. Patterns for dominant components and diffraction patterns of particles produced because of $P$. glomerata activity are shown. (Se), elemental Se; (Te), elemental tellurium. Typical diffraction patterns are shown from one of several determinations.

to protonation caused by the accessibility of carboxyl groups with a $\mathrm{pKa}$ below $\mathrm{pH} 3$ and demonstrated the role of EPS in formation of the metal nanoparticles (Armendariz et al., 2004). Several proteins and associated EPS from several bacterial strains have been shown to play a role in the generation and stability of various metal nanoparticles, including AuNPs, silver nanoparticles (AgNPs), cadmium nanoparticles
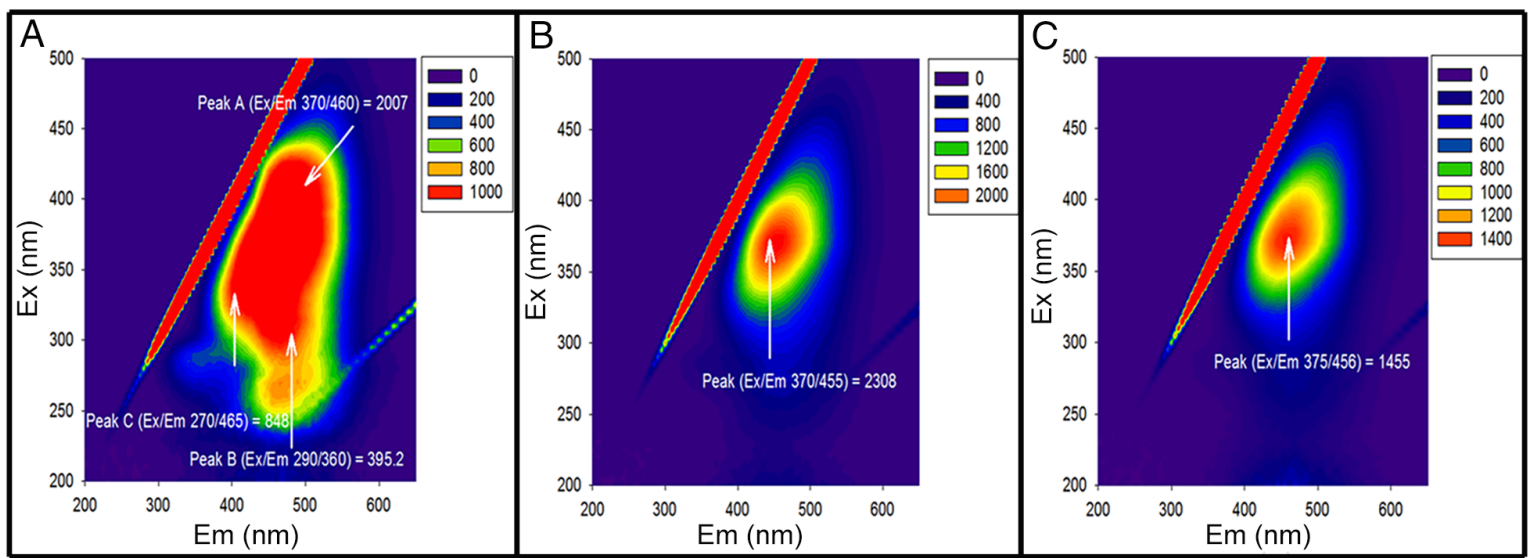

Fig. 4. EEM fluorescence spectra of (A) soluble EPS and (B) Se- or (C) tellurium-bound EPS obtained from $P$. glomerata culture medium. Phoma glomerata was grown in AP1 liquid media amended with $1 \mathrm{mM} \mathrm{Na}_{2} \mathrm{SeO}_{3}$ or $\mathrm{Na}_{2} \mathrm{TeO}_{3}$ for 30 days at $25^{\circ} \mathrm{C}$ in the dark on an orbital shaking incubator at $125 \mathrm{rpm}$. Colour intensities are in arbitrary units, and typical spectra are shown from one of at least three examinations with typical relative standard deviations of about $5 \%$.

(C) 2020 The Authors. Environmental Microbiology published by Society for Applied Microbiology and John Wiley \& Sons Ltd., 
(CdSNPs), Se nanoparticles (SeNPs), and Te nanoparticles (TeNPs) (Ahmad, et al., 2003; Sweeney et al., 2004; Birla et al., 2009; Aborode et al., 2015; Jain et al., 2015; Borghese et al., 2016). EPS can govern the surface charge of Se nanoparticles and also their size and shape (Jain et al., 2015). Functional groups characteristic of proteins and carbohydrates from EPS can stabilize spherical Se nanoparticles maintaining their shape and colloidal properties (Jain et al., 2015). Similar findings have been observed for biotransformation of tellurite to elemental Te with a loosely bound EPS fraction (Mal et al., 2017).

\section{Fourier transform infrared and thermogravimetric/ differential thermal analysis of elemental Se and Te formed by P. glomerata}

Fourier transform infrared (FTIR) spectroscopy can measure the wavelength and intensity of the absorption of infrared (IR) radiation by samples. The vibrations of a structural repeat unit can be used to identify different polypeptides and proteins from the IR spectral data. There are nine characteristic IR absorption bands, which are amide $\mathrm{A}$, amide $\mathrm{B}$, and amide I-VII. The most significant vibrational bands of a protein backbone usually fall in the amide I and amide II bands. $\mathrm{C}=\mathrm{O}$ stretch vibrations account for about $80 \%$ of the peptide linkages, which usually indicate protein secondary structural components in the amide I band $\left(1700-1600 \mathrm{~cm}^{-1}\right)$. The amide II band usually illustrates in-plane $\mathrm{NH}$ bending and $\mathrm{CN}$ stretching (Kong and Yu, 2007). Details of the characteristic IR bands of peptide linkages and vibration modes can be found in the study by Banker (1992). FTIR spectra of the purified Se and Te nanoparticles generated by $P$. glomerata indicated the presence of various capping biomolecules on the nanoparticle surfaces (Fig. 5A and C). These are substances produced as a result of biotic activity, e.g. proteins and amino acids, which can associate with nanoparticles and affect their properties including size (Jain et al., 2015; Mal et al., 2017; Li and Gadd, 2017; Piacenza et al., 2018a,b; Liang et al., 2019; Liu et al., 2019). The wave numbers of the maxima for the main bands revealed in the FTIR spectra are labelled in Fig. 5A and $\mathrm{C}$. The typical protein bands were attributable to amide I at $1637.76 \mathrm{~cm}^{-1}$ for SeNPs (Fig. 5A) and $1637.15 \mathrm{~cm}^{-1}$ for TeNPs (Fig. 5C), some low-intensity amide II at $1454.58 \mathrm{~cm}^{-1}$ (symmetrical stretching vibrations of $-\mathrm{COO}$ ), and amide III at $1336.90 \mathrm{~cm}^{-1}$ were detected for SeNPs (Fig. 5A). These observations match other results for Se nanoparticles synthesized by Azospirillum thiophilum and Alternaria alternata (Sarkar et al., 2011; Tugarova et al., 2017). The typical polysaccharide vibration regions are usually detected within the range of $1000-1200 \mathrm{~cm}^{-1}$. Polysaccharide peaks at
$1084.79 \mathrm{~cm}^{-1}$ and $1045.11 \mathrm{~cm}^{-1}$ were detected for SeNPs (Fig. 5A) while peaks at $1081.82 \mathrm{~cm}^{-1}$ were found for TeNPs (Fig. 5C). These peaks were attributable to aromatic in-plane $\mathrm{C}-\mathrm{H}$ bending (Sharma et al., 2014). The strong broad peak at $3000-3500 \mathrm{~cm}^{-1}$ could be attributed to the amine $\mathrm{N}-\mathrm{H}$ stretching vibration and occurred at $3303.51 \mathrm{~cm}^{-1}$ for SeNPs (Fig. $5 \mathrm{~A}$ ) and at $3303.84 \mathrm{~cm}^{-1}$ for TeNPs (Fig. 5C) (Krimm and Bandekar, 1986; Sarkar et al., 2011; Sharma et al., 2014). Even after several purification steps (see Methods), these results clearly demonstrated the strong attachment of proteins and polysaccharides as capping biomacromolecules on the SeNPs and TeNPs. These data are in line with the EEM results (Fig. 4) and other relevant findings for biosynthesised Se nanoparticles (Sarkar et al., 2011; Sharma et al., 2014; Tugarova et al., 2017).

Thermogravimetric analysis (TGA), derivative thermogravimetry (DTG), and differential thermal analysis (DTA) were carried out for the Se-/Te-containing particles formed by $P$. glomerata. The TG/DTA thermogram is shown in Fig. $5 \mathrm{~B}$ and D. For elemental Se formed by P. glomerata (Fig. 5B), the initial total weight loss of $4.86 \%$ observed at temperatures up to $150^{\circ} \mathrm{C}$ is attributable to the removal of adsorbed moisture and some organic volatiles, which are also associated with the derivative peak $A$ as shown in Fig. 5B. Between $150^{\circ} \mathrm{C}$ and $230^{\circ} \mathrm{C}$, the total weight loss was $23.57 \%$, which may be related to low-molecular weight organic substances (LMWOSs). Between $150^{\circ} \mathrm{C}$ and $230^{\circ} \mathrm{C}$, the total weight loss was $58.5 \%$, which resulted from the decomposition of fungal biomass and extract derivatives, which is associated with the derivative peak $\mathrm{C}$ as shown in Fig. 5B. Similar thermogravimetric observations have been observed for Se-containing derivatives synthesized from Cordyceps militaris polysaccharide (Zhu et al., 2016). Similar results were obtained from the elemental Te formed by $P$. glomerata (Fig. 5D). The FTIR and TGA results illustrate the association of extracellular protein and exopolysaccharide with the nanoparticles, and their role in stabilizing the size and shapes of $\mathrm{Se}$ and $\mathrm{Te}$ nanoparticles can be inferred and supported by previous research (Jain et al., 2015; Mal et al., 2017; Piacenza et al., 2018a,b; Liang et al., 2019).

As suggested from the above results, the formation of elemental Se and Te, confirmed by XRD analysis, occurred both intracellularly and extracellularly, as has been found for many other bacteria and fungi. There are several mechanisms involved in the formation of biogenic $\mathrm{Se}$ and Te nanoparticles, such as those mediated by intracellular proteins and extracellular EPS. It was previously shown that the formation of biogenic $\mathrm{Se}$ and Te nanoparticles was strongly influenced by the presence of EPS, which can be a complex mixture of extracellular proteins, lipids, extracellular DNA, humic substances, 


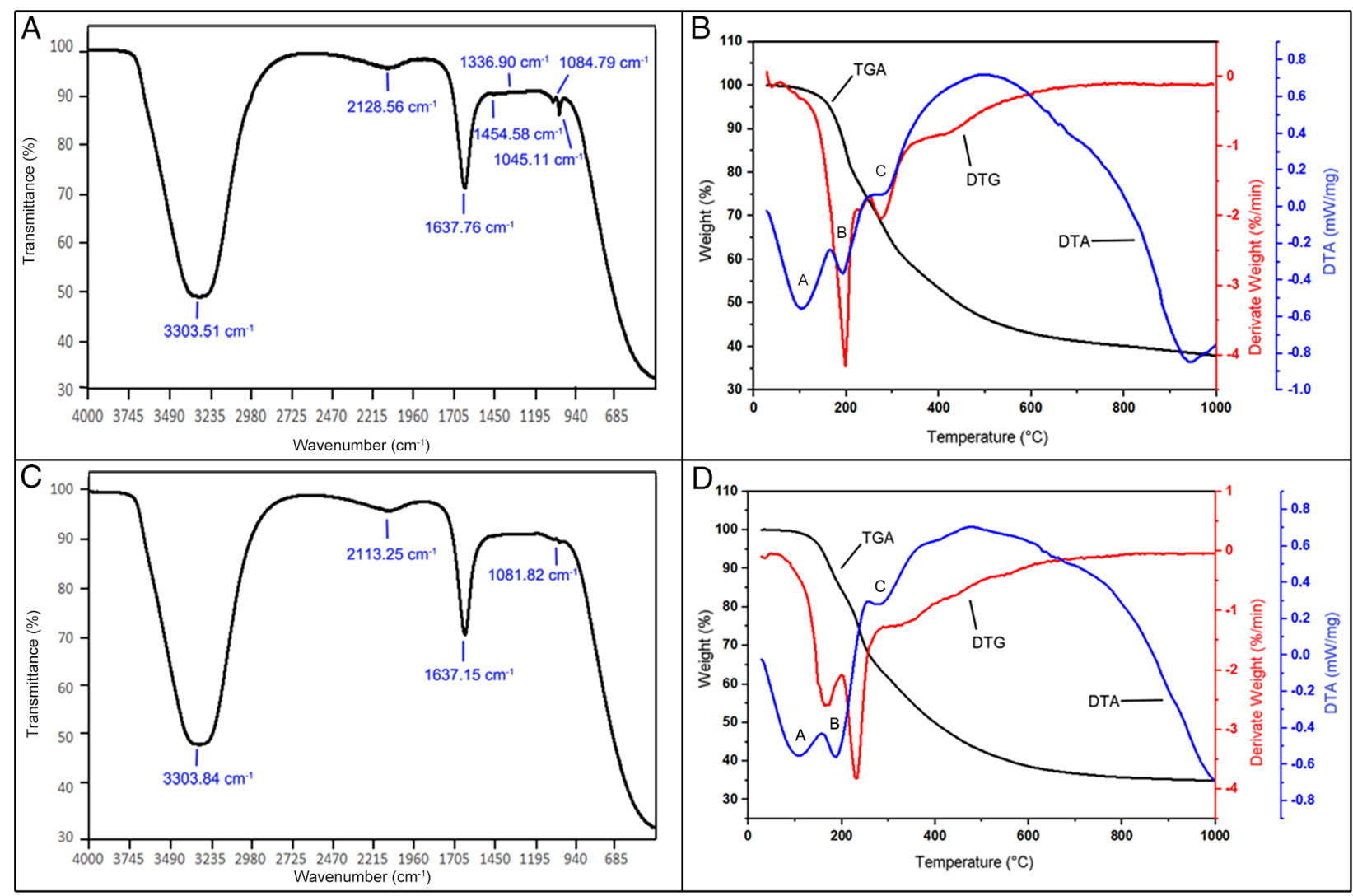

Fig. 5. Fourier transform infrared spectra and thermogravimetric analysis (TGA) of SeNPs (A, C) and TeNPs (B, D) generated by $P$. glomerata. Phoma glomerata was grown in AP1 liquid media amended with $1 \mathrm{mM} \mathrm{Na}_{2} \mathrm{SeO}_{3}$ or $\mathrm{Na}_{2} \mathrm{TeO}_{3}$ for 30 days at $25^{\circ} \mathrm{C}$ in the dark on an orbital shaking incubator at $125 \mathrm{rpm}$. Typical spectra are shown from one of at least three examinations with typical relative standard deviations of about $5 \%$. DTG, derivative thermogravimetry; DTA, differential thermal analysis.

and polysaccharides providing a multiplicity of functional groups (Sarkar et al., 2011; Sharma et al., 2014; Tugarova et al., 2017; Piacenza et al., 2018a,b). Several researchers have previously demonstrated a role for EPS and protein in capping elemental Se and Te produced by fungi and their roles in particle stabilization and the prevention of aggregation (Jain et al., 2015; Mal et al., 2017; Piacenza et al., 2018a,b).

\section{Distribution and concentration of Se and Te in Kisgruva sulfide ores}

Sequential extraction and speciation were performed on Kisgruva sulfide ores 450 and 459 to determine total concentrations of Se and Te species adsorbed onto oxide minerals and bound to organic matter (Bullock et al. 2018). Amounts of $\mathrm{Se}$ and $\mathrm{Te}$ species adsorbed to charged surfaces were determined by a phosphate buffer extraction method (Fig. 6, blue), while the amounts and speciation of $\mathrm{Se}$ and Te adsorbed to organic matter were examined by a sodium hydroxide extraction method (Fig. 6, orange). The Aqua regia residues method was used for total concentrations of Se and Te (Fig. 6, grey). Both selenite $\left(\mathrm{SeO}_{3}{ }^{2-}\right)$ and tellurite $\left(\mathrm{TeO}_{3}{ }^{2-}\right)$ were identified in sulfide ore crust samples by the extraction methods used (Fig. 6), but elemental forms $\left(\mathrm{Se}^{0}\right.$ and $\left.\mathrm{Te}^{0}\right)$ or selenate $\left(\mathrm{SeO}_{4}{ }^{2-}\right)$ /tellurate $\left(\mathrm{TeO}_{4}{ }^{2-}\right)$ were not detected. For sample 450, the proportions of Se and Te species adsorbed to charged surfaces of, e.g. oxide minerals were $5.66 \%$ and $6.89 \%$, the proportions of Se and Te species associated with organic matter were $8.67 \%$ and $24.49 \%$, and the proportions of Se and Te bound to non-extractable matter were $85.67 \%$ and $70.90 \%$ respectively. Of the extractable Se $(14.3 \%$ of the total Se), only $39.5 \%$ remained with oxide minerals, with $60.5 \%$ being bound to organic matter [Se(-II)]. For extracted $\mathrm{Te}$ (31.4\% of the total Te), $22 \%$ was adsorbed to oxide minerals, and $78 \%$ bound to organic matter. Similar results were observed for sample 459 , where the proportions of Se and Te species adsorbed to oxide minerals were $5.63 \%$ and $4.43 \%$, the proportions of $\mathrm{Se}$ and $\mathrm{Te}$ adsorbed to organic matter were $21.35 \%$ and $19.74 \%$, and the proportions of $\mathrm{Se}$ and $\mathrm{Te}$ adsorbed to nonextractable matter were $73.03 \%$ and $77.27 \%$ 


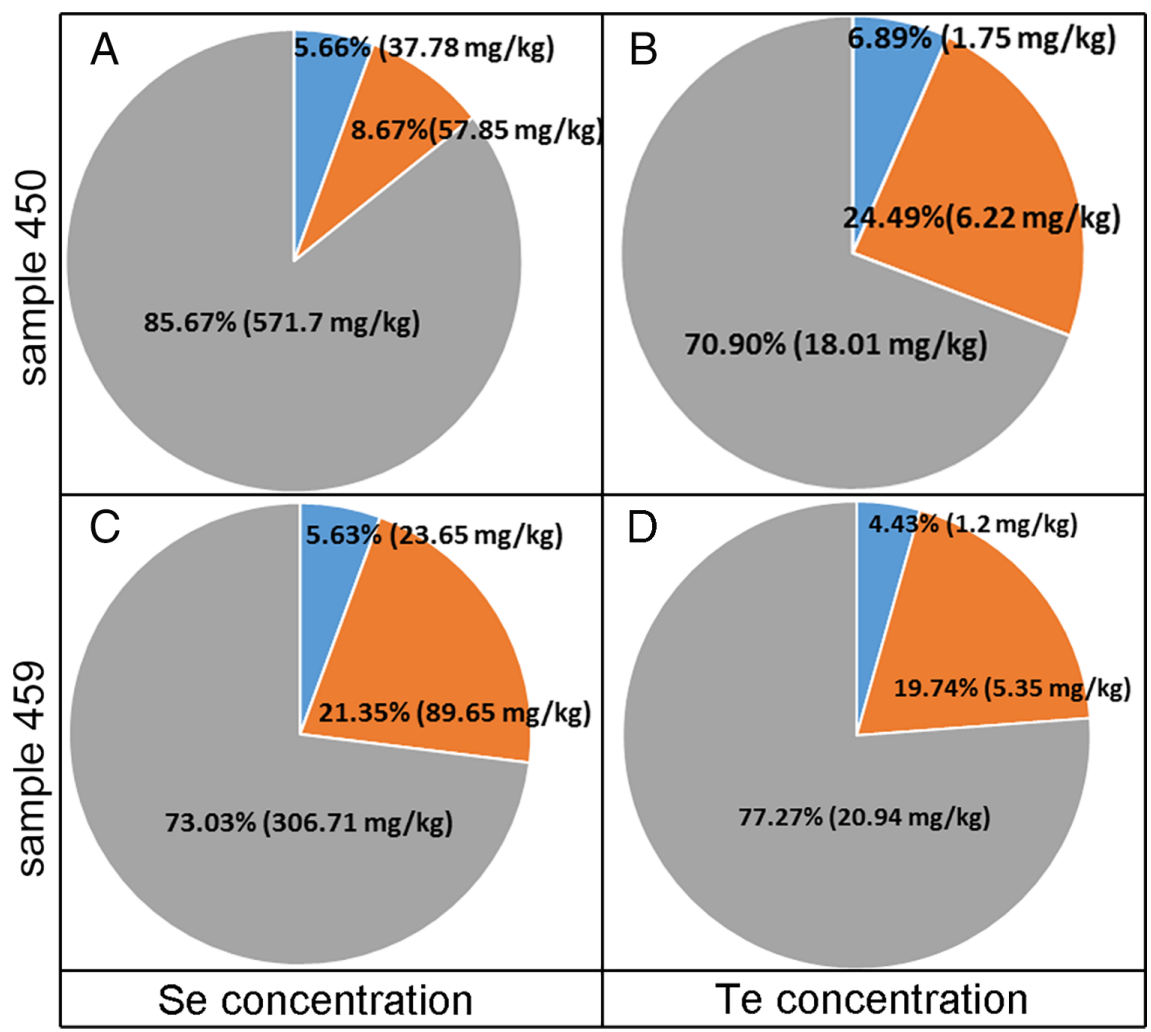

Fig. 6. Se and Te speciation determined by phosphate buffer (blue), sodium hydroxide (orange) and aqua regia residues (grey) extraction methods for ore samples 450 and 459. ( $\square$ ) Concentrations of $\mathrm{Se}$ or Te on charged surfaces, such as oxides or clay minerals, assessed through phosphate buffer extraction. () Concentrations of Se or Te bound to organic matter assessed through $\mathrm{NaOH}$ extraction. ( $)$ Total extractable $\mathrm{Se}$ or $\mathrm{Te}$ assessed through aqua regia residues extraction after the previous sequential extraction procedures. All values shown are means of at least three measurements with typical relative standard deviations of about $5 \%$. respectively. Of the extractable Se ( $27 \%$ of total Se), only $20.94 \%$ remained with oxide minerals, with $79.10 \%$ bound to organic matter $(\mathrm{Se}(-\mathrm{II}))$. For extracted $\mathrm{Te}$ ( $24.2 \%$ of total $\mathrm{Te}$ ), $20.94 \%$ was adsorbed to oxide minerals, and $79.10 \%$ bound to organic matter (Fig. 6).

\section{$\mathrm{pH}$ changes and tolerance, polysaccharide and protein production in sulfide ore amended liquid media}

Phoma glomerata could grow in the presence of $1 \%$ Kisgruva sulfide ores 450 or 459 over a 30 days incubation period. When ores 450 and 459 were suspended in sterile Milli-Q water, the suspension $\mathrm{pH}$ values were pH 3.9 and 7.9 respectively. There were significant changes in medium $\mathrm{pH}$ values on addition of the sulfide ore samples compared to the control. The initial medium $\mathrm{pH}$ for $P$. glomerata grown in ore-free AP1 medium was
$\mathrm{pH}$ 6.3. Compared to the control, the addition of sample 450 lowered the $\mathrm{pH}$ from $\mathrm{pH} 6.3$ to $\mathrm{pH} 2.6$ and remained acidic. Sample 459 increased the $\mathrm{pH}$ from $\mathrm{pH} 6.3$ to $\mathrm{pH} 8.3$ and remained alkaline (Table 1). Tolerance indices (TIs) were used to compare biomass yields grown in AP1 medium with or without the sulfide ore samples (Table 1). A TI value lower than $100 \%$ indicated growth inhibition. Phoma glomerata was able to grow in the presence of sulfide ores 450 and 459 for 30 days at $25^{\circ} \mathrm{C}$. However, P. glomerata showed a $70.6 \%$ and $64.6 \%$ reduction of growth in the presence of samples 450 and 459 respectively. The altered $\mathrm{pH}$ was likely to be contributing to this inhibition as well as any toxic effects arising from the ore samples.

The presence of Kisgruva sulfide ore also had an effect on exopolysaccharide production by $P$. glomerata. The concentration of exopolysaccharide produced by

Table 1. The $\mathrm{pH}$, polysaccharide and total protein content of fungal culture supernatant, and $\mathrm{Tl}$, after growth of $P$. glomerata in liquid AP1 medium for 30 days at $25^{\circ} \mathrm{C}$ in the dark in the presence or absence of Kisgruva ore samples 450 and 459 . All measurements are means of at least three replicates with typical relative standard deviations of about $5 \%$.

\begin{tabular}{llrrr}
\hline & $\mathrm{pH}$ & $\mathrm{TI}(\%)$ & Polysaccharide content $\left(\mathrm{mg} \mathrm{I}^{-1}\right)$ & ${\text { Protein content }\left(\mathrm{mg} \mathrm{I}^{-1}\right)}$ \\
\hline Control & 6.3 & 100.0 & $25.8 \pm 0.6$ & $102.8 \pm 1.3$ \\
Sample 450 & 2.6 & 70.6 & $11.7 \pm 0.3$ & $34.9 \pm 0.9$ \\
Sample 459 & 8.3 & 64.6 & $7.5 \pm 0.5$ & $51.3 \pm 0.7$ \\
\hline
\end{tabular}

(C) 2020 The Authors. Environmental Microbiology published by Society for Applied Microbiology and John Wiley \& Sons Ltd., 
Table 2. Elemental composition (\% by mass) of Kisgruva sulfide ore samples 450 and 459 before and after growth of $P$. glomerata in liquid medium for 30 days at $25^{\circ} \mathrm{C}$ in the dark, as determined using XRF. Most elements are expressed as oxides.

\begin{tabular}{lcccc}
\hline Element & $\begin{array}{c}\text { Initial composition } \\
\text { sample 450 }\end{array}$ & $\begin{array}{c}\text { Composition after fungal growth } \\
\text { sample 450 }\end{array}$ & $\begin{array}{c}\text { Initial composition } \\
\text { sample 459 }\end{array}$ & $\begin{array}{c}\text { Composition after fungal growth } \\
\text { sample 459 }\end{array}$ \\
\hline $\mathrm{Sum}$ & $100 \%$ & $100 \%$ & $100 \%$ & $100 \%$ \\
$\mathrm{Fe}_{2} \mathrm{O}_{3}$ & 30.44 & 31.65 & 28.07 & 31.52 \\
$\mathrm{SO}_{3}$ & 39.93 & 39.76 & 30.66 & 28.93 \\
$\mathrm{SiO}_{2}$ & 9.71 & 7.08 & 19.88 & 17.85 \\
$\mathrm{P}_{2} \mathrm{O}_{5}$ & 1.69 & 5.78 & 0.089 & 0.81 \\
$\mathrm{Al}_{2} \mathrm{O}_{3}$ & 8.43 & 5.36 & 11.98 & 10.19 \\
$\mathrm{MgO}$ & 4.92 & 3.45 & 6.29 & 5.24 \\
$\mathrm{~K}_{2} \mathrm{O}$ & 0.32 & 0.94 & 1.06 & 2.46 \\
$\mathrm{Cu}$ & 1.75 & 2.15 & 0.24 & 0.29 \\
$\mathrm{TiO}$ & 0.16 & 0.17 & 0.40 & 0.35 \\
$\mathrm{Cl}$ & 0.14 & 0.62 & 0.01 & 0.87 \\
$\mathrm{Zn}$ & 2.10 & 2.51 & 0.51 & 0.65 \\
$\mathrm{Na}{ }_{2} \mathrm{O}$ & 0 & 0 & 0.29 & 0.05 \\
$\mathrm{Se}$ & 0.04 & 0.06 & 0.02 & 0.02 \\
$\mathrm{CaO}$ & 0.15 & 0.20 & 0.24 & 0.49 \\
$\mathrm{MnO}$ & 0.09 & 0.09 & 0.19 & 0.19 \\
$\mathrm{As}$ & 0.02 & 0.02 & 0.02 & 0.02 \\
$\mathrm{~Pb}$ & 0.04 & 0.05 & 0.01 & 0.01 \\
$\mathrm{Co}$ & 0.02 & 0.02 & 0.04 & 0.04 \\
$\mathrm{~W}$ & 0.06 & 0.07 & 0.01 & 0.02 \\
\end{tabular}

Data shown are average values from at least three measurements with typical relative standard deviations of about $5 \%$.

P. glomerata grown in control ore-free liquid AP1 medium was $25.8 \mathrm{mg} \mathrm{I}^{-1}$ (Table 1). The exopolysaccharide concentration from $P$. glomerata grown with sample 450 in AP1 medium was reduced to $11.7 \mathrm{mg} \mathrm{l}^{-1}$, with a greater reduction being observed for sample $459\left(7.5 \mathrm{mg} \mathrm{I}^{-1}\right)$ (Table 1). Extracellular protein production correlated with the pattern of exopolysaccharide production. Compared to the control, the amount of extracellular protein decreased after growth with the Kisgruva sulfide ore samples. Control $P$. glomerata grown in AP1 medium produced extracellular protein at around $102.8 \mathrm{mg} \mathrm{I}^{-1}$ (Table 1). In the presence of samples 450 and 459, the protein concentrations dropped to $34.9 \mathrm{mg} \mathrm{l}^{-1}$ and $51.3 \mathrm{mg} \mathrm{l}^{-1}$ respectively (Table 1 ). Such reductions largely reflected the inhibitory effects of the ores on growth of $P$. glomerata.

\section{Composition of sulfide ore before and after fungal growth}

Elements present in the sulfide ore samples were determined by X-ray fluorescence (XRF). Se and Te were present within the sulfide ores in pyrite and chalcopyrite (samples 450 and 459), which contained up to $688 \mathrm{ppm}$ Se and 81 ppm Te (Bullock et al., 2018). There were no significant differences observed in the composition of the sulfide ores 450 and 459 before and after fungal growth, probably because any changes in elemental composition mediated by the fungus were small in relation to total element concentration (Table 2).

\section{Fungal accumulation of Se and Te from sulfide ore}

Phoma glomerata was used for further experiments on Se and Te accumulation when interacting with the sulfide ores. Phoma glomerata was grown on polished flat surfaces of samples 450 and 459 for 30 days on malt extract agar. About $50 \mathrm{~cm}^{3}$ malt extract agar (MEA, LabM Ltd, Bury, Lancashire, UK) (autoclaved at $121^{\circ} \mathrm{C}, 15 \mathrm{~min}$ ) were cooled to a temperature of around $50^{\circ} \mathrm{C}$ prior to pouring in $180 \mathrm{~mm}$ diameter Petri dishes. Samples 450 and 459 , pre-sterilized by oven-drying at $105^{\circ} \mathrm{C}$ to constant weight, were placed centrally in the Petri dishes with the polished flat surface facing upwards. Dialysis membranes (Focus Packaging and Design, Louth, UK) were sterilized by autoclaving twice at $121^{\circ} \mathrm{C}$ for $15 \mathrm{~min}$ in Milli-Q water, and used to cover the agar with or without the ore sample. These served to separate the fungus from the medium, but still allow access to diffusible nutrients, and enable easy removal of the biomass. Inocula consisted of a $10 \mathrm{~mm}$ diameter core cut from the margins of an actively growing fungal colony placed in the centre of the membrane disc. Plates were sealed with parafilm and incubated at $25^{\circ} \mathrm{C}$ in the dark for the duration of the experiments. Control and sample-amended plates for each experiment were made from the same batch of MEA powder. After 30 days incubation, fungal biomass on samples 450 and 459 was removed and laser ablation mapping was carried out on the sample surfaces. Laser ablation maps showed Se and Te to a low extent before fungal growth, even though Se was generally high throughout the pyrite phase (Figs. $7 \mathrm{C}$ and $8 \mathrm{C}$ ). For Se 


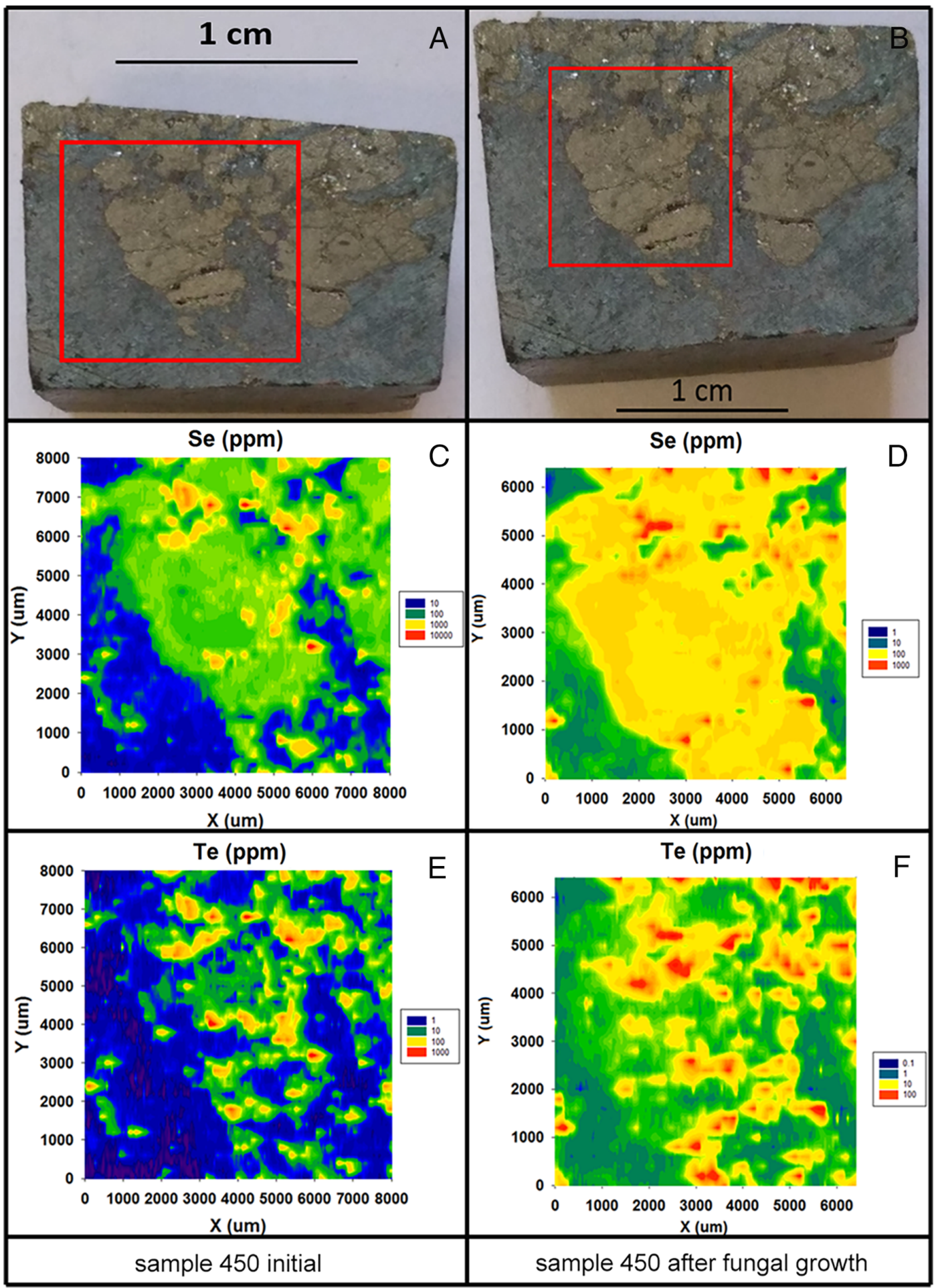

Fig. 7. Laser ablation inductively-coupled plasma mass spectrometry (LA-ICP-MS) elemental maps of Se and Te distribution on predominantly inclusion-free pyrite phases from Kisgruva sulfide ore sample 450 before and after being grown with $P$. glomerata for 30 days at $25^{\circ} \mathrm{C}$ in the dark. Scale bar $=1 \mathrm{~cm}$. Typical spectra are shown from one of at least three determinations.

and Te, concentrations were highest towards the edges of the pyrite for samples 450 and 459 (Figs. 7C, E and $8 \mathrm{C}, \mathrm{E})$. As well as a high content throughout pyrite, Se and Te also showed localized areas of high concentration, in some instances up to $10000 \mathrm{ppm}$ and $1000 \mathrm{ppm}$ respectively (Figs. 7 and 8). Although the selected pyrite 


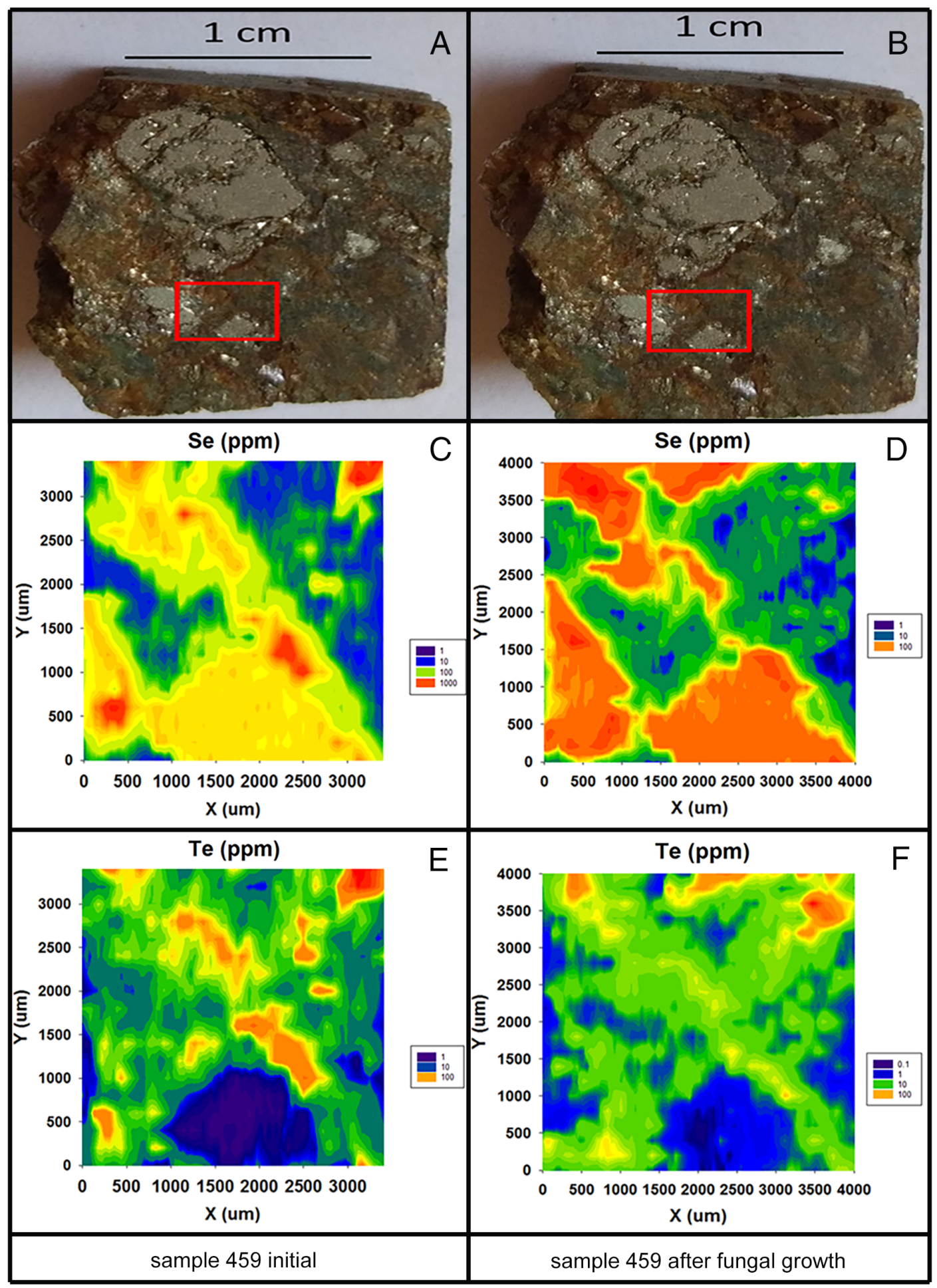

Fig. 8. Laser ablation inductively coupled plasma mass spectrometry (LA-ICP-MS) element maps of Se and Te distribution on predominantly inclusion-free pyrite phases from Kisgruva sulfide ore sample 459 before and after being grown with $P$. glomerata for 30 days at $25^{\circ} \mathrm{C}$ in the dark. Scale bar $=1 \mathrm{~cm}$. Typical spectra are shown from one of at least three determinations.

crystals were generally inclusion-free, these Se and Te hotspots may correspond to micron-sized $\mathrm{Se}^{2-}$ and $\mathrm{Te}^{2-}$ deposits (Bullock et al., 2018). After growth with
P. glomerata, Se and Te hotspot concentrations for sample 450 dropped to $1000 \mathrm{ppm}$ and $100 \mathrm{ppm}$ respectively (Fig. 7), while for sample 459, concentrations decreased

(C) 2020 The Authors. Environmental Microbiology published by Society for Applied Microbiology and John Wiley \& Sons Ltd., Environmental Microbiology, 22, 2346-2364 
Table 3. Concentrations of all elements in Kisgruva sulfide ore samples 450 and 459 before and after growth with $P$. glomerata for 30 days at $25^{\circ} \mathrm{C}$ in the dark. Data shown are average values from at least three measurements with typical relative standard deviations of about $5 \%$.

\begin{tabular}{|c|c|c|c|c|c|c|}
\hline \multirow{2}{*}{$\begin{array}{l}\text { Element } \\
(\mathrm{ppm})\end{array}$} & \multicolumn{3}{|c|}{ Sample 450} & \multicolumn{3}{|c|}{ Sample 459} \\
\hline & Before & After & $E F$ & Before & After & $\mathrm{EF}^{1}$ \\
\hline $\mathrm{Fe}$ & 390041 & 169915 & 1.00 & 633668 & 216849 & 1.00 \\
\hline $\mathrm{Cu}$ & 476 & 256 & 1.23 & 2124 & 402 & 0.55 \\
\hline As & 408 & 168 & 0.95 & 376 & 137 & 1.06 \\
\hline $\mathrm{Se}$ & 645 & 218 & 0.78 & 688 & 158 & 0.67 \\
\hline $\mathrm{Ag}$ & 26 & 14 & 1.24 & 62 & 15 & 0.71 \\
\hline $\mathrm{Te}$ & 49 & 14 & 0.66 & 81 & 23 & 0.83 \\
\hline $\mathrm{Au}$ & 0.2 & 0.1 & 1.15 & 0.2 & 0.1 & 1.46 \\
\hline $\mathrm{Hg}$ & 0.7 & 0.4 & 1.31 & 1.4 & 1.3 & 2.71 \\
\hline $\mathrm{Pb}$ & 1274 & 471 & 0.85 & 189 & 125 & 1.93 \\
\hline $\mathrm{Bi}$ & 17 & 5 & 0.68 & 30 & 9 & 0.88 \\
\hline
\end{tabular}

EF indicates the enrichment factor that is expressed relative to the iron in the ore samples, before and after fungal growth. An EF value $<1$ indicates an elemental decrease.

to $100 \mathrm{ppm}$ for both Se and Te (Fig. 8). These results correspond with $\mathrm{Se}$ and Te removal from the ores and enrichment in the fungus after growth of $P$. glomerata (Table 3).

Samples 450 and 459 were high in other chalcophilic elements, which show a chemical affinity to Se and Te, such as Fe (380 041 ppm, 633668 ppm), Cu (476 ppm, 2124 ppm), As (408 ppm, 376 ppm), Ag (26 ppm, $62 \mathrm{ppm})$ and $\mathrm{Bi}(17 \mathrm{ppm}, 30 \mathrm{ppm})$ respectively. The sulfide ore samples contained an average of $0.05 \%$ total organic carbon (TOC) (data not shown). Using laser ablation ICP-MS analysis of polished ore surfaces, it was found that certain elements in the sulfide ore samples showed a reduction after growth with $P$. glomerata, as revealed by the enrichment factors (expressed relative to the iron concentration before and after fungal growth). An EF value $<1$ indicate an elemental decrease, and therefore removal and enrichment in the fungal biomass, and this was clear for Se and Te with EF values ranging from 0.66 to 0.83 (Table 3). As mentioned previously, changes in $\mathrm{Se}$ and $\mathrm{Te}$ localization in the sulfide ores were confirmed by LA-ICP-MS element mapping (Figs. 7 and 8 ). Together, these results demonstrate that $P$. glomerata can accumulate metal(loids) from the sulfide ores.

The interactions of microorganisms with metalliferous ores have been studied for many years, being relevant to understanding the geomicrobiology of elemental cycling and mineral transformations in the environment as well as for industrial exploitation. The ability of certain bacteria and archaea to extract metals from ores and concentrates is well known and the basis of commercial metal bioleaching (Schippers et al., 2013; Johnson et al., 2013; Johnson, 2014). Fungi are also capable of metal bioleaching from ores, with secreted organic acids being a key component of the process (Burgstaller and Schinner, 1993; Mehta et al., 2010; Anjum et al., 2010; Biswas et al., 2013; Schippers et al., 2013; Yang et al., 2019,
2020). However, fungal bioleaching has not been demonstrated for Se or Te species, the most important Se transformations being reduction or methylation (Gadd, 1993; Chasteen and Bentley, 2003; Rosenfeld et al., 2017). The production of elemental $\mathrm{Se} / \mathrm{Te}$ species results in $\mathrm{Se} / \mathrm{Te}$ immobilization and has been investigated in the context of element biorecovery from solution, and soil and water bioremediation by prokaryotes and fungi (Lawson and Macy, 1995; Cantafio et al., 1996; Soda et al., 2012; Espinosa-Ortiz et al., 2015b, 2016b; Eswayah et al., 2016; Nancharaiah et al., 2016; Rosenfeld et al., 2017; Liang and Gadd, 2017). In this work, we have demonstrated the capability of a model fungus $P$. glomerata to mediate $\mathrm{Se}$ and Te transformations, resulting in Se or Te nanoparticle formation, and the involvement of biomacromolecules (proteins and polysaccharides) in this process. We have also shown that this organism can directly interact with a Se-/Tecontaining sulfide ore sample causing changes in metalloid speciation and accompanied by accumulation of the metalloids by the fungus and removal from the substrate. Fungal activity is therefore resulting in element fractionation, redistribution and concentration. To our knowledge, this is the first demonstration of such a phenomenon in a mineral ore and adds further understanding of fungal roles in metalloid geomicrobiology and environmental cycling.

\section{Experimental procedures}

\section{Organism, media and culture conditions}

Phoma glomerata ([Corda] Wollenw. and Hochapfel) from the Geomicrobiology Group culture collection was used for experiments. Previous work has already demonstrated its ability for iron oxide nanoparticle and nanosilver formation (Birla et al., 2009; Gudadhe et al., 2011; 
Gade et al., 2014). Phoma glomerata was routinely maintained on malt extract agar (MEA) (Sigma-Aldrich, St. Louis, MO, USA) at $25^{\circ} \mathrm{C}$ in the dark, and AP1 medium (composition detailed below) was used for experiments in liquid medium. Sodium selenite $\left(\mathrm{Na}_{2} \mathrm{SeO}_{3}\right)$ (Sigma-Aldrich ) or sodium tellurite $\left(\mathrm{Na}_{2} \mathrm{TeO}_{3}\right)$ (Alfa Aesar, Lancashire, UK) were used at a $1 \mathrm{mM}$ final concentration to examine the effect of these Se or Te oxyanions on growth.

The $100 \mathrm{ml}$ of AP1 liquid cultures of $P$. glomerata in 250-ml Erlenmeyer conical flasks were maintained on an orbital shaking incubator (Infors Multitron Standard, Rittergasse, Switzerland) at $125 \mathrm{rpm}$ at $25^{\circ} \mathrm{C}$ in the dark. For the liquid cultures, $P$. glomerata was grown for 5 days on AP1 agar medium after which $10 \times 6 \mathrm{~mm}$ diameter inoculum plugs were taken from the margins of actively growing colonies using sterile cork borers (autoclaved at $121^{\circ} \mathrm{C}, 15 \mathrm{~min}$ ) and inoculated into AP1 liquid medium. AP1 liquid medium consists of $\left(\mathrm{L}^{-1}\right.$ Milli- $Q$ water) (Merck Millipore, Billerica, MA, USA): D-glucose $30 \mathrm{~g}$ (Merck, Readington Township, NJ, USA), $\left(\mathrm{NH}_{4}\right)_{2} \mathrm{SO}_{4} 5 \mathrm{~g}$ (Sigma-Aldrich), $\mathrm{KH}_{2} \mathrm{PO}_{4} 0.5 \mathrm{~g}$ (SigmaAldrich), $\mathrm{MgSO}_{4} \cdot 7 \mathrm{H}_{2} \mathrm{O} 0.2 \mathrm{~g}$ (VWR, Radnor, PA, USA), $\mathrm{CaCl}_{2} \cdot 6 \mathrm{H}_{2} \mathrm{O} 0.05 \mathrm{~g}$ (VWR), $\mathrm{NaCl} 0.1 \mathrm{~g}$ (Sigma-Aldrich), $\mathrm{FeCl}_{3} \cdot 6 \mathrm{H}_{2} \mathrm{O} 2.5 \mathrm{mg}$ (Sigma-Aldrich), and trace metals: $\mathrm{ZnSO}_{4} \cdot 7 \mathrm{H}_{2} \mathrm{O} 4 \mathrm{mg}$ (VWR), $\mathrm{MnSO}_{4} \cdot 4 \mathrm{H}_{2} \mathrm{O} 4 \mathrm{mg}$ (VWR), and $\mathrm{CuSO}_{4} \cdot 5 \mathrm{H}_{2} \mathrm{O} 0.4 \mathrm{mg}$ (VWR). All chemicals, apart from glucose, were prepared as $1 \mathrm{M}$ stock solutions and autoclaved separately $\left(121^{\circ} \mathrm{C}, 15 \mathrm{~min}\right)$ before appropriately combining the required volumes to reach the desired final concentrations for AP1 liquid medium. Sodium selenite $\left(\mathrm{Na}_{2} \mathrm{SeO}_{3}\right)$ or sodium tellurite $\left(\mathrm{Na}_{2} \mathrm{TeO}_{3}\right)$ stock solution (1 $\mathrm{M}$ ) in Milli-Q water were membrane filtered (cellulose nitrate, $0.2 \mu \mathrm{m}$ pore diameter, Whatman, Maidstone, Kent, UK), and added to sterile AP1 liquid medium $\left(121^{\circ} \mathrm{C}, 15 \mathrm{~min}\right)$ at room temperature to a final concentration of $1 \mathrm{mM}$. After autoclaving, the liquid medium was adjusted to $\mathrm{pH} 5$ using $1 \mathrm{M} \mathrm{HCl}$. Phoma glomerata grown without $\mathrm{Se}$ or Te was used as the control. For solid AP1 media, $15 \mathrm{~g} \mathrm{I}^{-1}$ Milli-Q water Agar No 1 (Oxoid) was used.

\section{Effect of Se and Te on Phoma glomerata}

Liquid cultures of $P$. glomerata were harvested after 30 days and the biomass separated by centrifugation at $4000 \mathrm{rpm}(4880 \mathrm{~g})$ for $30 \mathrm{~min}$ and washed twice with sterile Milli-Q water (autoclaved at $121^{\circ} \mathrm{C}, 15 \mathrm{~min}$ ). Nanoparticle formation in association with fungal biomass grown with $1 \mathrm{mM} \mathrm{Na}_{2} \mathrm{SeO}_{3}$ or $1 \mathrm{mM} \mathrm{Na}_{2} \mathrm{TeO}_{3}$ was examined using scanning electron microscopy (SEM). Fungal pellets grown in the presence of $1 \mathrm{mM} \mathrm{Na}_{2} \mathrm{SeO}_{3}$ or $\mathrm{Na}_{2} \mathrm{TeO}_{3}$ for 30 days were cut in half using a sterile scalpel (Swann-Morton, Sheffield, UK) and fixed in $2.5 \%(\mathrm{~V} /$ $v_{\text {aq }}$ ) triple-distilled glutaraldehyde in $5 \mathrm{mM} \mathrm{1,4-piperazine}$ $N, N^{\prime}$ bis(2-ethane sulfonic acid) (PIPES) buffer, $\mathrm{pH} 7.2$, for at least $24 \mathrm{~h}$ at room temperature. The $\mathrm{pH}$ of $5 \mathrm{mM}$ PIPES buffer was adjusted using $1 \mathrm{M} \mathrm{NaOH}$ and a Corning $\mathrm{pH}$ meter 120 and electrode (Corning Incorporated, Corning, NY, USA). After fixation, samples were rinsed twice in $5 \mathrm{mM}$ PIPES buffer, $\mathrm{pH} 7.2$ (15 min per rinse) and then dehydrated through a graded ethanol series [50\%-100\% $\left(v / v_{\text {aq }}\right), 15 \mathrm{~min}$ per step]. Samples were then critical point dried using a liquid $\mathrm{CO}_{2}$ BAL-TEC CPD 0.30 critical point dryer (BAL-TEC company, Canonsburg, PA, USA) and subsequently mounted on aluminium stubs using carbon adhesive tape and stored in a desiccator at room temperature. Prior to electron microscopy, samples were coated with $10 \mathrm{~nm} \mathrm{Au/Pd}$ using a Cressington 208HR sputter coater (Ted Pella, Redding, CA, USA) and examined using a Philips XL30 environmental scanning electron microscope (ESEM) (Philips XL 30 ESEM FEG) operating at an accelerating voltage of $15 \mathrm{kV}$.

For confocal microscopy, cultured mycelia in AP1 medium without or supplemented with $1 \mathrm{mM} \mathrm{Na}_{2} \mathrm{SeO}_{3}$ or $\mathrm{Na}_{2} \mathrm{TeO}_{3}$ were harvested by centrifugation $(13000 \mathrm{~g}$, $30 \mathrm{~min}$ ) after 30 days incubation and fixed in $4 \%$ paraformaldehyde (PFA) in phosphate buffered saline (PBS) at $4{ }^{\circ} \mathrm{C}$ overnight, and then permeabilized with $0.5 \%$ Triton $\mathrm{X}-100$ in PBS for 30 min prior to the addition of Molecular Probes Hoechst 33342 (nuclear staining dye) (SigmaAldrich). The working concentration of Hoechst 33342 was $15 \mu \mathrm{g} \mathrm{ml}^{-1}$. After $15 \mathrm{~min}$ incubation with Hoechst 33342 in the dark, mycelia were washed three times in $0.01 \mathrm{M}$ PBS, pH 7.2 before confocal microscopy. For each sample, 5-10 fields were chosen at random and 0.9-mm thick sections were collected on a laser scanning confocal microscope (Carl Zeiss LSM700; Carl Zeiss Microscopy $\mathrm{GmbH}$, Jena, Germany) using a 40x objective. Maximum intensity projections were made and automatic settings used to locate objects in each image. The offset was set at -65 and objects were filtered using the long axis at $<100 \mu \mathrm{m}$. Each image was checked manually with at least three replicates.

\section{Characterization of Se and Te nanoparticles}

Particles present in the fungal supernatant were harvested by centrifugation at a series of speeds $(4 \mathrm{k}, 8 \mathrm{k}$ and $13 \mathrm{k} \times \mathrm{g}$ ), each centrifugation step lasting $30 \mathrm{~min}$ until the particles in the supernatant were separated from the biomass. Harvested particles were rinsed through a graded ethanol series $\left[50 \%-100 \%\left(v / v_{a q}\right), 15 \mathrm{~min}\right.$ per step], then rinsed three times with a $20 \%(w / v)$ sodium dodecyl sulfate (SDS) solution and finally rinsed three times with autoclaved Milli-Q water $\left(121^{\circ} \mathrm{C}, 15 \mathrm{~min}\right)$ to remove remaining impurities. Particles were subsequently mounted on aluminium scanning electron 
microscopy stubs using carbon adhesive tape and stored in a desiccator at room temperature. Nanoparticles separated from the fungal supernatant were examined for elemental composition using energy-dispersive X-ray analysis (EDXA) before $\mathrm{Au} / \mathrm{Pd}$ coating the samples in order to exclude the Au/Pd peak. A Phoenix EDXA analysis system embedded within the ESEM was used for spectral analysis with an accelerating voltage of $20 \mathrm{kV}$ for at least $100 \mathrm{~s}$.

To further characterize the collected Se- and Tecontaining particles, particle size was measured using Fiji software (Schindelin et al., 2012), wherein a user-coded Java ImageJ plugin was employed to evaluate particlesize distribution (PSD) based on the diameter of particles. Approximately, 500 particles were randomly chosen for size measurements. To clarify the PSD, particles were divided into 8-12 groups according to their size range, and their size distribution was fitted according to the Gaussian distribution equation.

X-ray diffraction (XRD) was also employed to characterize the nanoparticles generated by $P$. glomerata. Diffraction patterns were recorded from 3 to $120^{\circ} 2-\theta$ using $\mathrm{Ni}$-filtered $\mathrm{Cu} \mathrm{K}$-alpha radiation, and scanning from 3 to $120^{\circ} 2-\theta$, counting for $300 \mathrm{~s}$ per step on a Panalytical Xpert Pro diffractometer using a X-celerator position sensitive detector. Mineral phases were identified with reference to patterns in the International Centre for Diffraction Data Powder Diffraction File (PDF).

\section{Fluorescent spectral characteristics of EPS}

Excitation emission matrix (EEM) fluorescence spectroscopy was used to assess the involvement of soluble EPS and Se- and Te-bound EPS in the formation of Se and Te NPs. All EEM spectra were measured using a fluorescence spectrophotometer (F-7000; Hitach, Japan) equipped with a $1.0 \mathrm{~cm}$ quartz cell and a thermostat bath. EEM spectra were collected from $200 \mathrm{~nm}$ to $700 \mathrm{~nm}$ in $2 \mathrm{~nm}$ increments by varying the excitation wavelength from $200 \mathrm{~nm}$ to $500 \mathrm{~nm}$ in $5 \mathrm{~nm}$ increments. The width of the excitation/emission slit was set at $5.0 \mathrm{~nm}$, and the scanning speed was set to $1200 \mathrm{~nm} \cdot \mathrm{min}^{-1}$. The response of the fluorometer to a Milli-Q water blank was subtracted from the fluorescence spectra recorded for samples containing EPS and $\mathrm{SeO}_{3}{ }^{2-} / \mathrm{TeO}_{3}{ }^{2-}$ under the same conditions (Song et al., 2012). EEM data were processed using SigmaPlot software, version 12.5 (Systat Software, San Jose, CA, USA).

\section{Fourier-transform infrared spectroscopy and thermogravimetric analysis}

To further characterize the elemental Se and Te particles formed by $P$. glomerata, FTIR analysis was used to identify the functional groups, which could be responsible for stabilizing or determining size and shape. IR spectra of the nanoparticles were recorded using a PerkinElmer Spectrum Two attenuated total reflectance Fourier transform infrared spectrometer (ATR-FTIR) (PerkinElmer, Waltham, MA, USA) equipped with a deuterated tryglycine sulfate (DTGS) detector and consisting of a golden gate single reflection diamond ATR accessory and $\mathrm{KBr}$ window. To minimize interferences from the external environment and maintain the consistency of experimental conditions, a background spectrum was recorded before each sample examination. Particles in the fungal supernatant were harvested by centrifugation as described above and after the washing step with Milli-Q water, the aqueous suspension was finally filtered through $0.45 \mu \mathrm{m}$ cellulose acetate membrane filters prior to analysis. Aliquots $(1 \mathrm{ml})$ from an aqueous suspension of SeNPs or TeNPs in Milli-Q water was placed on the metal O-ring on the diamond crystal and scanned at a range from 4000 to $450 \mathrm{~cm}^{-1}$, with a resolution of $4 \mathrm{~cm}^{-1}$ and recorded at an average of eight scans at room temperature. Each sample analysis was performed in triplicate.

In order to investigate the thermal degradation characteristics (decomposition temperature, thermal stability, degradation rate and exothermicity) of fungal-formed Se-/ Te-containing particles, thermogravimetric analysis (TGA) was employed. The TGA results can elucidate the thermal degradation properties of the nanoparticles and indicate the role of extracellular protein and exopolysaccharide in their stabilization. TGA was performed with a Netzsch STA 409PC TG/DTG/DTA analyser fitted with a SiC furnace (NETZSCH Group, Selb, Germany). Small amounts (4-8 $\mathrm{mg}$ ) of nanoparticle samples (harvested as described above) were placed in the platinum pan and heated from room temperature to $1000^{\circ} \mathrm{C}$ at an incremental rate of $10^{\circ} \mathrm{C}$ per min with dry $\mathrm{N}_{2}$ as the purge gas at a flow rate of $100 \mathrm{ml} \mathrm{min}{ }^{-1}$. The samples were maintained at $1000^{\circ} \mathrm{C}$ until they reached constant weight. The results obtained were expressed as a curve of mass loss as a function of temperature.

\section{Sequential extraction and metalloid speciation in Kisgruva sulfide ore}

To measure Se and Te content in the Kisgruva sulfide ore samples 450 (Northing/Easting-N59.59360 E009. 60893) and 459 (Northing/Easting-N59.59967 E009. 60966) (Bullock et al., 2018), sequential extraction and speciation were performed to determine total concentrations of Se and Te species adsorbed onto oxide minerals and organic matter. Speciation and total concentration analysis of the major elements in the Kisgruva sulfide ore samples was performed using an ICP-MS 7900, 
coupled to a HPLC 1100 (Agilent Technology, Japan). Concentrations of $\mathrm{Se}$ and $\mathrm{Te}$ species adsorbed to charged surfaces, such as oxide minerals, were determined by a phosphate buffer extraction method, while the concentrations and speciation of Se and Te adsorbed to organic matter were examined using sodium hydroxide extraction. The Aqua regia residues method was used for total extractable concentrations of Se and Te (Kulp and Pratt, 2004; Di Tullo et al., 2016). For the phosphate buffer extraction method, $0.1 \mathrm{M} \mathrm{K}_{2} \mathrm{HPO}_{4}-\mathrm{KH}_{2} \mathrm{PO}_{4}$ buffer at $\mathrm{pH} 7$ was used to desorb ligand-exchangeable $\mathrm{Se}(\mathrm{IV})$ and Te (IV) from charged surfaces on oxide minerals or clay particles. For this, $25 \mathrm{ml}$ of phosphate buffer was mixed with $1 \mathrm{~g}$ finely ground ore 450 or 459 in $50 \mathrm{ml}$ test tubes and shaken in a shaking incubator at room temperature at $125 \mathrm{rpm}$ for $2 \mathrm{~h}$. After shaking, tubes were centrifuged at $4000 \mathrm{rpm}(4880 \mathrm{~g})$ for $30 \mathrm{~min}$ at $4{ }^{\circ} \mathrm{C}$, and the supernatants harvested and retained in separate tubes. The remaining ore samples were rinsed with another $10 \mathrm{ml}$ autoclaved $\left(121^{\circ} \mathrm{C}, 15 \mathrm{~min}\right)$ Milli-Q water, and after shaking and centrifugation, the supernatants were mixed with the previous phosphate buffer extract (Kulp and Pratt, 2004). The sodium hydroxide extraction method was used for extracting tightly bound Se(IV) and $\mathrm{Te}$ (IV), and base-soluble inorganic and organic selenides. The ore residues remaining from phosphate buffer extraction were used for the sodium hydroxide extraction. In this method, $25 \mathrm{ml} 1 \mathrm{M} \mathrm{NaOH}$ was mixed with the ore residues in $50 \mathrm{ml}$ glass tubes and incubated in a water bath at $90^{\circ} \mathrm{C}$ for $2 \mathrm{~h}$. After incubation, tubes were cooled and centrifuged at $4000 \mathrm{rpm}(4880 \mathrm{~g})$ for $30 \mathrm{~min}$, supernatants being harvested and retained in separate tubes. The remaining ore samples were rinsed with another $10 \mathrm{ml}$ autoclaved $\left(121^{\circ} \mathrm{C}, 15 \mathrm{~min}\right)$ Milli-Q water, and after shaking and centrifugation, the supernatants were mixed with the previously obtained $\mathrm{NaOH}$ extract (Kulp and Pratt, 2004).The residues remaining from the previous sequential-extraction procedures were used to determine total Se and Te using the Aqua regia method [high purity hydrochloric and nitric acids (VWR International Ltd, Poole, UK)] in a heating block within a closed system. Residues were heated until they dissolved and were then tested for total Se and Te content (Kulp and Pratt, 2004; Di Tullo et al., 2016).

\section{Tolerance of P. glomerata to Kisgruva sulfide ore}

To investigate effects of the sulfide ores on fungal growth, Kisgruva samples 450 and 459 were ground into powder with a pestle and mortar (Milton Brook, Sturminster Newton, Dorset, UK), and sterilized at $105^{\circ} \mathrm{C}$ for 7 days prior to experiments. Phoma glomerata was grown in $100 \mathrm{ml}$ AP1 liquid medium with $1 \mathrm{~g}$ sulfide ore (samples 450 and 459) in 250-ml Erlenmeyer conical flasks on an orbital shaking incubator at $125 \mathrm{rpm}$ at $25^{\circ} \mathrm{C}$ in the dark for 30 days. Kisgruva sulfide ore samples 450 or 459 were incubated in AP1 medium without $P$. glomerata as a control. Fungal biomass was aseptically harvested after 30 days incubation by centrifugation at $4880 \times g$ for $30 \mathrm{~min}$ and washed twice with autoclaved Milli-Q water. The supernatants were further clarified by filtering through $0.45 \mu \mathrm{m}$ cellulose acetate membrane filters prior to analysis. Growth was evaluated using a tolerance index (TI) calculated as follows: (dry weight of sulfide ore sample exposed mycelium/dry weight of control mycelium). Fungal biomass was oven-dried at $105^{\circ} \mathrm{C}$ to constant weight and then ground to a powder using a pestle and mortar. A pH 210 Microprocessor $\mathrm{pH}$ Meter (Hanna Instruments, Woonsocket, RI, USA) was used for $\mathrm{pH}$ measurements of the culture supernatants. All experiments were conducted at least in triplicate.

\section{Production of extracellular protein and}

exopolysaccharide by P. glomerata grown with Kisgruva sulfide ore

To examine the effect of sulfide ore on the production of extracellular protein and exopolysaccharide, supernatants harvested after growth of $P$. glomerata in liquid media containing $1 \mathrm{~g}$ sulfide ore (sample 450 or 459 ) for 30 days were centrifuged $(12000 \mathrm{~g}, 30 \mathrm{~min})$ and the supernatants clarified by filtering through $0.45 \mu \mathrm{m}$ cellulose acetate membrane filters. After that, the supernatant was purified by dialysis ( $3500 \mathrm{Da}$ membrane) for $24 \mathrm{~h}$ at $4^{\circ} \mathrm{C}$ to remove any residual glucose. Extracellular protein was determined using a Bradford protein assay (Bio-Rad Laboratories, Watford, UK) using bovine serum albumin as standard. Polysaccharide content was determined by the phenol-sulfuric acid method using glucose as the standard (Dubois et al., 1956).

\section{$X R F$ spectroscopy for elemental composition of the Kisgruva sulfide ore}

Partial elemental composition of the Kisgruva sulfide ore 450 and 459 before and after growth with $P$. glomerata for 30 days at $25^{\circ} \mathrm{C}$ was determined by XRF using a Philips PW2424 sequential XRF spectrometer fitted with a RhKa source, and regularly calibrated with certified standard materials. Kisgruva sulfide ore, before and after fungal growth, was harvested after 30 days incubation samples by centrifugation $(4880 \mathrm{~g}, 30 \mathrm{~min})$ and after removal of the supernatant, was washed and resuspended in $50 \mathrm{ml}$ sterile $\left(121^{\circ} \mathrm{C}, 15 \mathrm{~min}\right)$ Milli-Q water at ambient temperature, and centrifuged again $(4880 \mathrm{~g}, 30 \mathrm{~min})$, this procedure being repeated twice. The ore sample was then dried in an oven at $105^{\circ} \mathrm{C}$ for 7 days to constant weight, ground into powder using a 
pestle and mortar, and then placed in a $\varnothing 27 \mathrm{~mm}$ pellet mould and compacted under a load of $75 \mathrm{kN}$ for $5 \mathrm{~min}$ and $150 \mathrm{kN}$ for a further $10 \mathrm{~min}$ prior to analysis. The results are expressed as oxides.

Laser ablation of Se- or Te-containing Kisgruva sulfide ores after growth of $\mathrm{P}$. glomerata

Sulfide ore samples were cut into blocks, with one surface polished for trace element analysis. X-ray mapping was performed using a New Wave laser ablation system UP213 nm (New Wave Research, Fremont, CA, USA) coupled to an ICP-MS Agilent 7900 (Agilent Technologies, Tokyo, Japan). The laser beam was fired with a spot size of $100 \mu \mathrm{m}$, the repetition rate was set at $10 \mathrm{~Hz}$, and at $50 \mu \mathrm{m} \mathrm{s}^{-1}$ ablation speed with $1 \mathrm{~J} \mathrm{~cm}^{2}$ energy. A $15 \mathrm{~s}$ period was applied as a warm-up period before ablation, with a $15 \mathrm{~s}$ delay between each ablation. To make sure of restricted oxide formation and maximize the sensitivity, a NIST Glass 612 was used to optimize all the parameters and settings. A reaction cell with 3.0$3.5 \mathrm{ml} \mathrm{min}{ }^{-1}$ hydrogen gas was employed to remove any possible interferences and optimize the Se sensitivity. MASS-1 synthetic polymetal sulfide (US Geological Survey, Restron, VA, USA) and $\mathrm{FeS}^{-1}$ certified reference materials (CRMs) (Slim Group, University of Quebec, Quebec, Canada) were used for quantification.

\section{Speciation and total concentration analysis of Kisgruva sulfide ores after growth of $P$. glomerata}

Speciation and total concentration analysis of the major elements in the Kisgruva sulfide ore samples was performed with an ICP-MS 7900, coupled to a HPLC 1100 (Agilent Technology, Japan). A Hamilton PRP-100 column was used with a mobile phase of $1 \mathrm{ml} \mathrm{min}^{-1}$ (10 $\mathrm{mmol} \mathrm{L}^{-1}, \mathrm{pH} 10$ ) phosphate buffer (Sigma-Aldrich). The $100 \mu$ of samples were injected at $4^{\circ} \mathrm{C}$ with an autosampler. Lens parameters were optimized with a solution of $1 \mu \mathrm{g} \mathrm{L}^{-1}$ of $\mathrm{Ga}, \mathrm{Y}, \mathrm{Tl}$ and $\mathrm{Ce}$, with $3.5 \mathrm{ml} \mathrm{min}^{-1}$ hydrogen used in the reaction cell. The $10 \mu \mathrm{g} \mathrm{L}^{-1} \mathrm{Ge}$ solution was employed as an internal standard to correct any plasma fluctuation and remove any interferences during Se measurement. Isotopes ${ }^{72} \mathrm{Ge},{ }^{77} \mathrm{Se},{ }^{78} \mathrm{Se},{ }^{125} \mathrm{Te}$ and ${ }^{126} \mathrm{Te}$ were also monitored. Commercial sodium selenite (Alpha Aesar, Haverhill, MA, USA), sodium selenate (Alpha Aesar), sodium tellurite (Alpha Aesar) and telluric acid (Sigma-Aldrich) were used as standards for total concentration, speciation, external calibration and quantification.

\section{Statistical analysis}

All data presented are means of at least three replicates: error bars represent one standard error either side of the mean. SigmaPlot, version 12.5, was used to perform statistical analyses. One-way ANOVA tests on means were performed.

\section{Acknowledgements}

G.M.G. gratefully acknowledges research support from Natural Environment Research Council (NE/M010910/1) under the NERC Security of Supply of Mineral Resources Grant Programme: Tellurium and Selenium cycling and supply (TeaSe). G.M.G. also gratefully acknowledges additional support of the Geomicrobiology Group from NERC [NE/M011275/1 $\left.\left(\mathrm{COG}^{3}\right)\right]$. The authors also gratefully acknowledge the help of Dr Yongchang Fan (Materials and Photonics Systems Group, University of Dundee, Dundee, DD1 5EH, Scotland UK) for assistance with scanning electron microscopy, and Dr Alan Prescott and Dr Christopher Lipina (School of Life Sciences, University of Dundee, Dundee, DD1 5EH, Scotland UK) for assistance with confocal microscopy.

\section{Compliance with ethical standards}

\section{Ethics approval}

This article does not contain any studies with human participants or animals performed by any of the authors.

\section{References}

Aborode, F.A., Raab, A., Foster, S., Lombi, E., Maher, W., Krupp, E.M., and Feldmann, J. (2015) Selenopeptides and elemental selenium in Thunbergia alata after exposure to selenite: quantification method for elemental selenium. Metallomics 7: 1056-1066.

Ahmad, A., Senapati, S., Khan, M.I., Kumar, R., and Sastry, M. (2003) Extracellular biosynthesis of monodisperse gold nanoparticles by a novel extremophilic actinomycete, Thermomonospora sp. Langmuir 19: 3550-3553.

Anjum, F., Bhatti, H.N., Asgher, M., and Shahid, M. (2010) Leaching of metal ions from black shale by organic acids produced by Aspergillus Niger. Appl Clay Sci 47: 356-361.

Armendariz, V., Herrera, I., Peralta-videa, J.R., Joseyacaman, M., Troiani, H., Santiago, P., and GardeaTorresdey, J.L. (2004) Size controlled gold nanoparticle formation by Avena sativa biomass: use of plants in nanobiotechnology. J Nanopart Res 6: 377-382.

Baesman, S.M., Bullen, T.D., Dewald, J., Zhang, D., Curran, S., Islam, F.S., et al. (2007) Formation of tellurium nanocrystals during anaerobic growth of bacteria that use Te oxyanions as respiratory electron acceptors. Appl Environ Microbiol 73: 2135-2143.

Bajaj, M., Schmidt, S., and Winter, J. (2012) Formation of $\mathrm{Se}(0)$ nanoparticles by Duganella sp. and Agrobacterium 
sp. isolated from Se-laden soil of north-East Punjab, India. Microb Cell Fact 11: 64.

Banker, J. (1992) Amide modes and protein conformation. Biochim Biophys Acta 1120: 123-143.

Birla, S.S., Tiwari, V.V., Gade, A.K., Ingle, A.P., Yadav, A.P., and Rai, M.K. (2009) Fabrication of silver nanoparticles by Phoma glomerata and its combined effect against Escherichia coli, Pseudomonas aeruginosa and Staphylococcus aureus. Lett Appl Microbiol 48: 173-179.

Biswas, S., Dey, R., Mukherjee, S., and Banerjee, P.C. (2013) Bioleaching of nickel and cobalt from lateritic chromite overburden using the culture filtrate of Aspergillus Niger. Appl Biochem Biotechnol 170: 1547-1559.

Bjerkgård, T. (2015) Massive sulfides in Norway. Geological Survey of Norway NGU Focus Nr 2, February 2015.

Borghese, R., Brucale, M., Fortunato, G., Lanzi, M., Mezzi, A., Valle, F., et al. (2016) Extracellular production of tellurium nanoparticles by the photosynthetic bacterium Rhodobacter capsulatus. J Hazard Mater 309: 202-209.

Brady, J.M., Tobin, J.M., and Gadd, G.M. (1996) Volatilization of selenite in aqueous medium by a Penicillium species. Mycol Res 100: 955-961.

Bullock, L.A., Perez, M., Armstrong, J.G., Parnell, J., Still, J., and Feldmann, J. (2018) Selenium and tellurium resources in Kisgruva Proterozoic volcanogenic massive sulphide deposit (Norway). Ore Geol Rev 99: 411-424.

Burgstaller, W., and Schinner, F. (1993) Leaching of metals with fungi. J Biotechnol 27: 91-116.

Cantafio, A.W., Hagen, K.D., Lewis, G.E., Bledsoe, T.L., Nunan, K.M., and Macy, J.M. (1996) Pilot-scale selenium bioremediation of San Joaquin drainage water with Thauera selenatis. Appl Environ Microbiol 62: 3298-3303.

Ceci, A., Kierans, M., Hillier, S., Persiani, A.M., and Gadd, G.M. (2015a) Fungal bioweathering of mimetite and a general geomycological model for lead apatite mineral biotransformations. Appl Environ Microbiol 81: 4955-4964.

Ceci, A., Rhee, Y.J., Kierans, M., Hillier, S., Pendlowski, H., Gray, N., et al. (2015b) Transformation of vanadinite $\left(\mathrm{Pb}_{5}\left(\mathrm{VO}_{4}\right)_{3} \mathrm{Cl}\right)$ by fungi. Environ Microbiol 17: 2018-2034.

Chasteen, T.G., and Bentley, R. (2003) Biomethylation of selenium and tellurium: microorganisms and plants. Chem Rev 103: 1-26.

Chen, W., Westerhoff, P., Leenheer, J.A., and Booksh, K. (2003) Fluorescence excitation-emission matrix regional integration to quantify spectra for dissolved organic matter. Environ Sci Technol 37: 5701-5710.

Debieux, C.M., Dridge, E.J., Mueller, C.M., Splatt, P., Paszkiewicz, K., Knight, I., et al. (2011) A bacterial process for selenium nanosphere assembly. Proc Nat Acad Sci USA 108: 13480-13485.

Di Tullo, P., Pannier, F., Thiry, Y., Le Hécho, I., and Bueno, M. (2016) Field study of time dependent selenium partitioning in soils using isotopically enriched stable selenite tracer. Sci Total Environ 562: 280-288.

Dubois, M., Gilles, K.A., Hamilton, J.K., Rebers, P.A., and Smith, F. (1956) Colorimetric method for determination of sugars and related substances. Anal Chem 28: 350-356.

Espinosa-Ortiz, E.J., Gonzalez-Gil, G., Saikaly, P.E., van Hullebusch, E.D., and Lens, P.N.L. (2015a) Effects of selenium oxyanions on the white-rot fungus
Phanerochaete chrysosporium. Appl Microbiol Biotechnol 99: 2405-2418.

Espinosa-Ortiz, E.J., Rene, E.R., van Hullebusch, E.D., and Lens, P.N.L. (2015b) Removal of selenite from wastewater in a Phanerochaete chrysosporium pellet based fungal bioreactor. Int Biodet Biodegrad 102: 361-369.

Espinosa-Ortiz, E.J., Pechaud, Y., Lauchnor, E., Rene, E.R., Gerlach, R., Peyton, B.M., et al. (2016a) Effect of selenite on the morphology and respiratory activity of Phanerochaete chrysosporium biofilms. Bioresour Technol 210: 138-145.

Espinosa-Ortiz, E.J., Rene, E.R., Pakshirajan, K., van Hullebusch, E.D., and Lens, P.N.L. (2016b) Fungal pelleted reactors in wastewater treatment: applications and perspectives. Chem Eng J 283: 553-571.

Espinosa-Ortiz, E.J., Shakya, M., Jain, R., Rene, E.R., van Hullebusch, E.D., and Lens, P.N.L. (2016c) Sorption of zinc onto elemental selenium nanoparticles immobilized in Phanerochaete chrysosporium pellets. Environ Sci Pollut Res Int 23: 21619-21630.

Espinosa-Ortiz, E.J., Rene, E.R., Guyot, F., van Hullebusch, E.D., and Lens, P.N.L. (2017) Biomineralization of tellurium and selenium-tellurium nanoparticles by the white-rot fungus Phanerochaete chrysosporium. Int Biodet Biodegrad 124: 258-266.

Eswayah, A.S., Smith, T.J., and Gardiner, P.H. (2016) Microbial transformations of selenium species of relevance to bioremediation. Appl Environ Microbiol 82: 4848-4859.

Gadd, G.M. (1993) Microbial formation and transformation of organometallic and organometalloid compounds. FEMS Microbiol Rev 11: 297-316.

Gadd, G.M. (2007) Geomycology: biogeochemical transformations of rocks, minerals, metals and radionuclides by fungi, bioweathering and bioremediation. Mycol Res 111: 3-49.

Gadd, G.M. (2010) Metals, minerals and microbes: geomicrobiology and bioremediation. Microbiol 156: 609-643.

Gade, A.K., Gaikwad, S.C., Duran, N., and Rai, M.K. (2014) Green synthesis of silver nanoparticles by Phoma glomerata. Micron 59: 52-59.

Gharieb, M.M., and Gadd, G.M. (1998) Evidence for the involvement of vacuolar activity in metal(loid) tolerance: vacuolar-lacking and-defective mutants of Saccharomyces cerevisiae display higher sensitivity to chromate, tellurite and selenite. Biometals 11: 101-106.

Gharieb, M.M., and Gadd, G.M. (2004) Role of glutathione in detoxification of metal(loid)s by Saccharomyces cerevisiae. Biometals 17: 183-188.

Gharieb, M.M., Kierans, M., and Gadd, G.M. (1999) Transformation and tolerance of tellurite by filamentous fungi: accumulation, reduction, and volatilization. Mycol Res 103: 299-305.

Gudadhe, J.A., Bonde, S.R., Gaikwad, S.C., Gade, A.K., and Rai, M.K. (2011) Phoma glomerata: a novel agent for fabrication of iron oxide nanoparticles. J Bionanosci 5: 138-142.

Guo, Y., Pan, D., Li, H., Sun, Y., Zeng, X., and Yan, B. (2013) Antioxidant and immunomodulatory activity of selenium exopolysaccharide produced by Lactococcus lactis subsp. Lactis. Food Chem 138: 84-89. 
Jacob, J.M., Lens, P.N.L., and Balakrishnan, R.M. (2016) Microbial synthesis of chalcogenide semiconductor nanoparticles: a review. J Microbial Biotechnol 9: 11-21.

Jain, R., Jordan, N., Weiss, S., Foerstendorf, H., Heim, K., Kacker, R., et al. (2015) Extracellular polymeric substances govern the surface charge of biogenic elemental selenium nanoparticles. Environ Sci Technol 49: 1713-1720.

Jiang, S., Ho, C.T., Lee, J.H., van Duong, H., Han, S., and Hur, H.G. (2012) Mercury capture into biogenic amorphous selenium nanospheres produced by mercury resistant Shewanella putrefaciens 200. Chemosphere 87: 621-624.

Johnson, D.B. (2014) Biomining - biotechnologies for extracting and recovering metals from ores and waste materials. Curr Opinion Biotechnol 30: 24-31.

Johnson, D.B., Grail, B.M., and Hallberg, K.B. (2013) A new direction for biomining: extraction of metals by reductive dissolution of oxidized ores. Minerals 3: 49-58.

Kim, Y.H., Lee, H.S., Kwon, H.J., Patnaik, B.B., Nam, K.W., Han, Y.S., et al. (2014) Effects of different selenium levels on growth and regulation of laccase and versatile peroxidase in white-rot fungus, Pleurotus eryngii. World $J$ Microbiol Biotechnol 30: 2101-2109.

Kirtzel, J., Ueberschaar, N., Deckert-Gaudig, T., Krause, K., Deckert, V., Gadd, G.M., and Kothe, E. (2020) Organic acids, siderophores, enzymes, and mechanical pressure for black slate bioweathering with the basidiomycete Schizophyllum commune. Environ Microbiol 22: 1535-1546.

Kong, J., and Yu, S. (2007) Fourier transform infrared spectroscopic analysis of protein secondary structures. Acta Biochem Biophys Sinica 39: 549-559.

Kotková, J., Kullerud, K., Šrein, V., Drábek, M., and Škoda, R. (2018) The Kongsberg silver deposits, Norway: $\mathrm{Ag}-\mathrm{Hg}-\mathrm{Sb}$ mineralization and constraints for the formation of the deposits. Miner Deposita 53: 531-545.

Krimm, S., and Bandekar, J. (1986) Vibrational spectroscopy and conformation of peptides, polypeptides, and proteins. Adv Protein Chem 38: 181-364.

Kulp, T.R., and Pratt, L.M. (2004) Speciation and weathering of selenium in upper cretaceous chalk and shale from South Dakota and Wyoming, USA. Geochim Cosmochim Acta 68: 3687-3701.

Lawson, S., and Macy, J. (1995) Bioremediation of selenite in oil refinery wastewater. Appl Microbiol Biotechnol 43: 762-765.

Li, D.B., Cheng, Y.Y., Wu, C., Li, W.W., Li, N., Yang, Z.C., et al. (2014) Selenite reduction by Shewanella oneidensis MR-1 is mediated by fumarate reductase in periplasm. Sci Rep 4: 3735.

Li, Q., and Gadd, G.M. (2017) Biosynthesis of copper carbonate nanoparticles by ureolytic fungi. Appl Microbiol Biotechnol 101: 7397-7407.

Liang, X., and Gadd, G.M. (2017) Metal and metalloid biorecovery using fungi. J Microbial Biotechnol 10: 1199-1205.

Liang, X., Perez, M.A.M.-J., Nwoko, K.C., Egbers, P., Feldmann, J., Csetenyi, L., and Gadd, G.M. (2019) Fungal formation of selenium and tellurium nanoparticles. Appl Microbiol Biotechnol 103: 7241-7259.
Liu, F., Csetenyi, L., and Gadd, G.M. (2019) Amino acid secretion influences the size and composition of copper carbonate nanoparticles synthesized by ureolytic fungi. Appl Microbiol Biotechnol 103: 7217-7230.

Mal, J., Nancharaiah, Y.V., Maheshwari, N., van Hullebusch, E.D., and Lens, P.N.L. (2017) Continuous removal and recovery of tellurium in an upflow anaerobic granular sludge bed reactor. J Hazard Mater 327: 79-88.

Mandal, D., Bolander, M.E., Mukhopadhyay, D., Sarkar, G., and Mukherjee, P. (2006) The use of microorganisms for the formation of metal nanoparticles and their application. Appl Microbiol Biotechnol 69: 485-492.

Mehta, K.D., Das, C., and Pandey, B.D. (2010) Leaching of copper, nickel and cobalt from Indian Ocean manganese nodules by Aspergillus Niger. Hydrometallurgy 105: 89-95.

Munoz, A.H.S., Kubachka, K., Wrobel, K., Corona, J.F.G., Yathavakilla, S.K.V., Caruso, J.A., and Wrobel, K. (2006) Se-enriched mycelia of Pleurotus ostreatus: distribution of selenium in cell walls and cell membranes/cytosol. J Agric Food Chem 54: 3440-3444.

Nancharaiah, Y.V., Venkata Mohan, S., and Lens, P.N.L. (2016) Biological and bioelectrochemical recovery of critical and scarce metals. Trends Biotechnol 34: 137-155.

Oremland, R.S., Herbel, M.J., Blum, J.S., Langley, S., Beveridge, T.J., Ajayan, P.M., et al. (2004) Structural and spectral features of selenium nanospheres produced by Se-respiring bacteria. Appl Environ Microbiol 70: 52-60.

Piacenza, E., Presentato, A., and Turner, R.J. (2018a) Stability of biogenic metal(loid) nanomaterials related to the colloidal stabilization theory of chemical nanostructures. Crit Rev Biotechnol 38: 1137-1156.

Piacenza, E., Presentato, A., Zonaro, E., Lampis, S., Vallini, G., and Turner, R.J. (2018b) Microbial-based bioremediation of selenium and tellurium compounds. In Biosorption, Vol. 2018, Derco, J., and Vrana, B. (eds). London, UK: IntechOpen, pp. 117-147.

Rosenfeld, C.E., Kenyon, J.A., James, B.R., and Santelli, C. M. (2017) Selenium (IV,VI) reduction and tolerance by fungi in an oxic environment. Geobiology 15: 441-452.

Sarkar, J., Dey, P., Saha, S., and Acharya, K. (2011) Mycosynthesis of selenium nanoparticles. Micro Nano Lett 6: 599-602.

Schindelin, J., Arganda-Carreras, I., Frise, E., Kaynig, V., Longair, M., Pietzsch, T., et al. (2012) Fiji: an open-source platform for biological-image analysis. Nat Methods 9: 676-682.

Schippers, A., Hedrich, S., Vasters, J., Drobe, M., Sand, W., and Willscher, S. (2013) Biomining: metal recovery from ores with microorganisms. In Geobiotechnology I. Advances in Biochemical Engineering/Biotechnology, Vol. 141, Schippers, A., Glombitza, F., and Sand, W. (eds). Berlin, Heidelberg: Springer, pp. 1-47.

Sharma, G., Sharma, A.R., Bhavesh, R., Park, J., Ganbold, B., Nam, J.S., and Lee, S.S. (2014) Biomolecule-mediated synthesis of selenium nanoparticles using dried Vitis vinifera (Raisin) extract. Molecules 19: 2761-2770.

Soda, S., Takahashi, H., Kagami, T., Miyake, M., Notaguchi, E., Sei, K., et al. (2012) Biotreatment of selenium refinery wastewater using pilot-scale granular sludge 
and swim-bed bioreactors augmented with a seleniumreducing bacterium Pseudomonas stutzeri NT-I. Jpn J Water Treat Biol 48: 63-71.

Song, W., Pan, X., and Zhang, D. (2012) Lead complexation of soluble and bound extracellular polymeric substances from activated sludge: characterized with fluorescence spectroscopy and FTIR spectroscopy. Biotechnol Biotechnol Equip 26: 3371-3377.

Sonkusre, P., Nanduri, R., Gupta, P., and Cameotra, S.S. (2014) Improved extraction of intracellular biogenic selenium nanoparticles and their specificity for cancer chemoprevention. J Nanomed Nanotechnol 5: 194.

Sweeney, R.Y., Mao, C., Gao, X., Burt, J.L., Belcher, A.M., Georgiou, G., and Iverson, B.L. (2004) Bacterial biosynthesis of cadmium sulfide nanocrystals. Chem Biol 11: 1553-1559.

Tugarova, A.V., Mamchenkova, P.V., Dyatlova, Y.A., and Kamnev, A.A. (2017) FTIR and Raman spectroscopic studies of selenium nanoparticles synthesised by the bacterium Azospirillum thiophilum. Spectrochim Acta A Mol Biomol Spectrosc 192: 458-463.

Vetchinkina, E., Loshchinina, E., Kursky, V., and Nikitina, V. (2013) Reduction of organic and inorganic selenium compounds by the edible medicinal basidiomycete Lentinula edodes and the accumulation of elemental selenium nanoparticles in its mycelium. $J$ Microbiol 51: 829-835.
Wei, Z., Kierans, M., and Gadd, G.M. (2012a) A model sheet mineral system to study fungal bioweathering of mica. Geomicrobiol J 29: 323-331.

Wei, Z., Hillier, S., and Gadd, G.M. (2012b) Biotransformation of manganese oxides by fungi: solubilization and production of manganese oxalate biominerals. Environ Microbiol 14: 1744-1753.

Wei, Z., Liang, X., Pendlowski, H., Hillier, S., Suntornvongsagul, K., Sihanonth, P., and Gadd, G.M. (2013) Fungal biotransformation of zinc silicate and sulphide mineral ores. Environ Microbiol 15: 2173-2186.

Yang, Y., Ferrier, J., Csetenyi, L., and Gadd, G.M. (2019) Direct and indirect bioleaching of cobalt from low grade laterite and pyritic ores by Aspergillus Niger. Geomicrobiol J 36: 940-949.

Yang, Y., Song, W., Ferrier, J., Liu, F., Csetenyi, L., and Gadd, G.M. (2020) Biorecovery of cobalt and nickel using biomass-free culture supernatants from Aspergillus Niger. Appl Microbiol Biotechnol 104: 417-425.

Zhang, L., Li, D., and Gao, P. (2012) Expulsion of selenium/protein nanoparticles through vesicle-like structures by Saccharomyces cerevisiae under microaerophilic environment. World J Microbiol Biotechnol 28: 3381-3386.

Zhu, Z.Y., Liu, F., Gao, H., Sun, H., Meng, M., and Zhang, Y. M. (2016) Synthesis, characterization and antioxidant activity of selenium polysaccharide from Cordyceps militaris. Int J Biol Macromol 93: 1090-1099. 